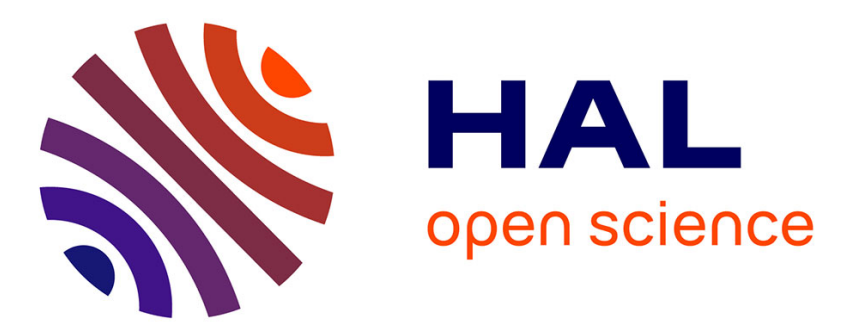

\title{
Autumnal precipitation distribution on the southern flank of the Alps: A numerical-model study of the mechanisms
}

\author{
François Gheusi, Huw C. Davies
}

\section{- To cite this version:}

François Gheusi, Huw C. Davies. Autumnal precipitation distribution on the southern flank of the Alps: A numerical-model study of the mechanisms. Quarterly Journal of the Royal Meteorological Society, 2004, 130 (601), pp.2125-2152. 10.1256/qj.03.06 . hal-00136323

\section{HAL Id: hal-00136323 https://hal.science/hal-00136323}

Submitted on 10 Aug 2021

HAL is a multi-disciplinary open access archive for the deposit and dissemination of scientific research documents, whether they are published or not. The documents may come from teaching and research institutions in France or abroad, or from public or private research centers.
L'archive ouverte pluridisciplinaire HAL, est destinée au dépôt et à la diffusion de documents scientifiques de niveau recherche, publiés ou non, émanant des établissements d'enseignement et de recherche français ou étrangers, des laboratoires publics ou privés.

\section{(c)(1)}

Distributed under a Creative Commons Attribution| 4.0 International License 


\title{
Autumnal precipitation distribution on the southern flank of the Alps:
}

A numerical-model study of the mechanisms

\author{
By FRANÇOIS GHEUSI* and HUW C. DAVIES \\ Institute for Atmospheric and Climate Science, ETH Zürich, Switzerland
}

\begin{abstract}
During the autumn there are frequent events of heavy precipitation on the southern slopes of the meso- $\alpha$ scale Alpine chain. Moreover, the accompanying climatology exhibits a distinctive spatial distribution with some meso- $\beta$-scale regions of enhanced precipitation such as the 'wet spot' in the vicinity of Lago Maggiore.

Possible mechanisms to account for the observed spatial distribution are established using a heuristic modelbased approach. It is shown using a mesoscale model that the response to a steady, horizontally uniform, and moisture-laden flow impinging upon a comparatively realistic representation of the Alpine chain can reproduce both the overall meso- $\alpha$-scale precipitation distribution and its meso- $\beta$-scale sub-structure. The nature of the simulated flow regime (over, around or intermediate) is sensitive to the strength of the ambient geostrophic flow and its modification in the planetary boundary layer. Contrariwise, the simulated precipitation distribution in the Lago Maggiore 'wet spot' is comparatively insensitive to the changes in direction of the incident geostrophic flow from south to south-west, and in strength in the range $10-30 \mathrm{~m} \mathrm{~s}^{-1}$, although there is a marked change in the structure of the near-Alpine flow. This systematic precipitation enhancement appears to be related to the relative strength and compensating effects of an easterly barrier jet tracking along the zonally elongated part of the Alps and an air stream channelled between the Maritime Alps and the Apennines.

Further evidence to the above interpretation of the meso- $\beta$-scale precipitation distribution is given with simulations conducted using a smoothed and schematic representation of the Alpine chain. Likewise, the sensitivity to the presence of a Lago Maggiore-like indentation of the topography is tested, and evidence is provided of a further 'indentation-induced' precipitation enhancement at the local scale.
\end{abstract}

\section{INTRODUCTION}

Autumnal events of heavy precipitation on the Alpine south side are related to the approach aloft of a narrow meridionally elongated trough (sic potential-vorticity streamer) with an associated co-aligned surface cold front. This synoptic setting (that prevails prior to the Alpine disruption of the front) favours precipitation on the Alpine south side since it is accompanied by a prolonged warm, moisture-laden air stream from the Mediterranean towards the main meso- $\alpha$-scale Alpine chain (Doswell et al. 1998; Massacand et al. 1998). The climatology of heavy-precipitation frequency for October (Fig. 1(a)) is documented in Frei and Schär (1998).

Inspection of Fig. 1 reveals that the spatial distribution is somewhat inhomogeneous with several meso- $\beta$-scale regions experiencing enhanced precipitation. These preferred regions appear to be linked to specific topographic features, such as Lago Maggiore. For single synoptic events such a local intensification of the precipitation over single valleys or basins can contribute to severe flash floods (e.g. Buzzi and Foschini 2000; Ferretti et al. 2000).

The relationship between topographic features and local precipitation enhancement prompted one of the scientific questions of the Mesoscale Alpine Programme (MAP) (Bougeault et al. 2001):

How do special configurations of topography with respect to the large-scale flow (especially, the moist air flow in the low levels), such as curved mountain ranges, valleys, etc., concentrate precipitation into severe downpours and produce flash floods? MAP Science Plan (1998)†.

\footnotetext{
* Corresponding author, present affiliation: Laboratoire d'A'erologie, 14 avenue E.Belin, F-31400 Toulouse, France. e-mail: ghef@aero.obs-mip.fr
} 

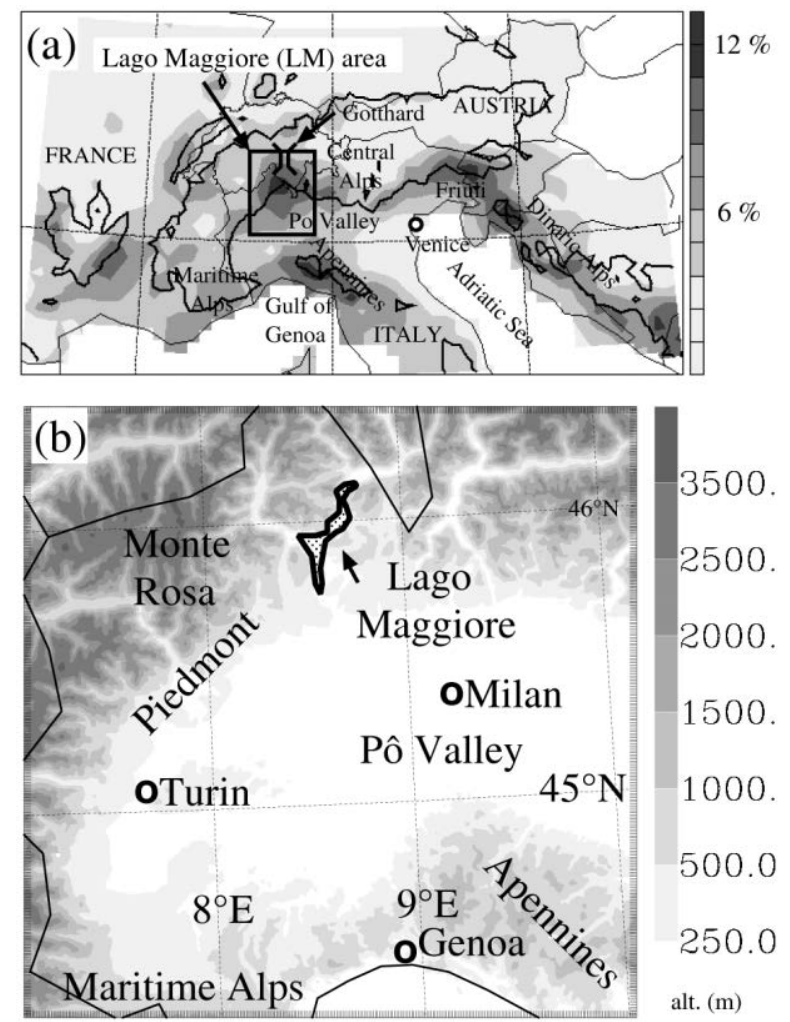

Figure 1. (a) Climatological frequency (\%) of days in October with precipitation exceeding $20 \mathrm{~mm}$. Analysis (version 4.0) retrieved from the MAP Data Center (http://www.map.ethz.ch); the database is described by Frei and Schär (1998). The heavy line represents the $800 \mathrm{~m}$ topographic contour. (b) Topography (m) of north-western Italy (grey scale).

Heavy-precipitation events are particularly frequent in October over the Lago Maggiore (hereafter LM) area (Fig. 1(a)). Here the topography forms a meso- $\beta$-scale indentation with a radius of curvature of about $50 \mathrm{~km}$, surrounded by high terrain and embedded within the meso- $\alpha$-scale arc of the Alpine chain (which has a radius of curvature of about $250 \mathrm{~km}$ ). The topography of the region as well as the referenced geographical locations are presented in Figs. 1(a) and (b).

In this study our objective is to examine and seek to elicit the fundamental factors accounting for this richly structured pattern of Alpine precipitation. Two recent studies of this genre used idealized topographies to represent the Alps (Schneidereit and Schär 2000, hereafter SS00; Rotunno and Ferretti 2001, hereafter RF01).

SS00 stressed the role of the concave shape of the chain in inducing convergence of the low-level flow and thereby favouring precipitation. The study helped to delineate diabatic-flow regimes over or around the obstacle for large-scale southerly flows. The flow-over regime, since it implies a strong uplift of the moist low layers, is favourable for orographic precipitation (Buzzi et al. 1998; Ferretti et al. 2000).

Nevertheless, heavy orographic precipitation may also be produced under certain conditions of flow-around regime. RF01 showed that the lateral variation of moisture in the incident flow can lead to a spatially differentiated flow response due to cloud diabatic effects. They emphasized the role of the barrier wind - an easterly low-level wind jet along the south side of the Alps, that is characteristic of the flow-around regime 
and is due to the subgeostrophic leftwards deviation of the slowing flow approaching the obstacle (see Pierrehumbert and Wyman (1985) and Marwitz (1987)). This jet can, within the Alpine concavity, lead to low-level convergence in combination with air directly advected from the south, and thereby enhance the precipitation over that area (over and above that due to direct upslope forcing).

In both SSO0 and RF01, small-scale topographic features such as the LM indentation were neglected. Moreover, the precipitation enhancement was found to be less spatially concentrated than in the observed climatology. In this paper we seek to complement the results of these previous studies by focusing attention on the influence of meso- $\beta$-scale orographic effects.

The higher frequency of heavy precipitation over given regions, such as the LM area, might result from local topography-induced flow regimes that are set up for a range of large-scale upstream flow conditions. This working hypothesis provides the motivation for adopting a strategy of prescribing an idealized large-scale flow upstream of a realistic representation of the Alps, and exploring the orographic flow and precipitation regimes that prevail for different specifications of that flow.

An idealized setting for a south-Alpine heavy-rain event was presented in Gheusi and Stein (2003). It has two basic ingredients, which are again retained in the present study:

(i) A stationary uniform upstream flow with a dominant southerly component, driving:

(ii) Conditionally convective moist air towards the Alps.

The nonlinearity, due to the elevated and complex topography of the Alps as well as the diabatic effects in the moist atmosphere, necessitates the use of a full-physics primitiveequation numerical model.

The strategy is as follows. In a first step the externally specified idealized flow impinges upon a comparatively realistic representation of the Alps and the neighbouring relief, and a sequence of simulations is performed to examine the dependence of the flow and precipitation distribution upon the strength and direction of the incident flow. In a second step a second series of simulations is performed with appropriate idealized representations of the topography to isolate some of the orographically induced mechanisms inferred from the first set of simulations.

The paper is arranged as follows: The physical setting and set-up of the numerical model are detailed in section 2 . The flow regimes obtained with various upstream flow conditions and the realistic topography are presented in section 3, and the accompanying moisture transports and precipitation distributions in section 4 . Simulations with idealized topography are considered in section 5, and finally the results are reviewed and commented upon in section 6 .

\section{PHYSICAL SETTING AND MODEL}

(a) Physical setting

The physical setting for the present study is displayed and summarized in Fig. 2. It comprises a horizontally uniform and stationary moist airflow impinging upon the topography, with the strength and direction assigned as case-dependent parameters. This incident flow (referred to hereafter as the large-scale flow or LS flow) corresponds to geostrophic balance with a prescribed ambient pressure gradient. Thus, far upstream of the topography the actual flow is characterized by an Ekman-like balance between 

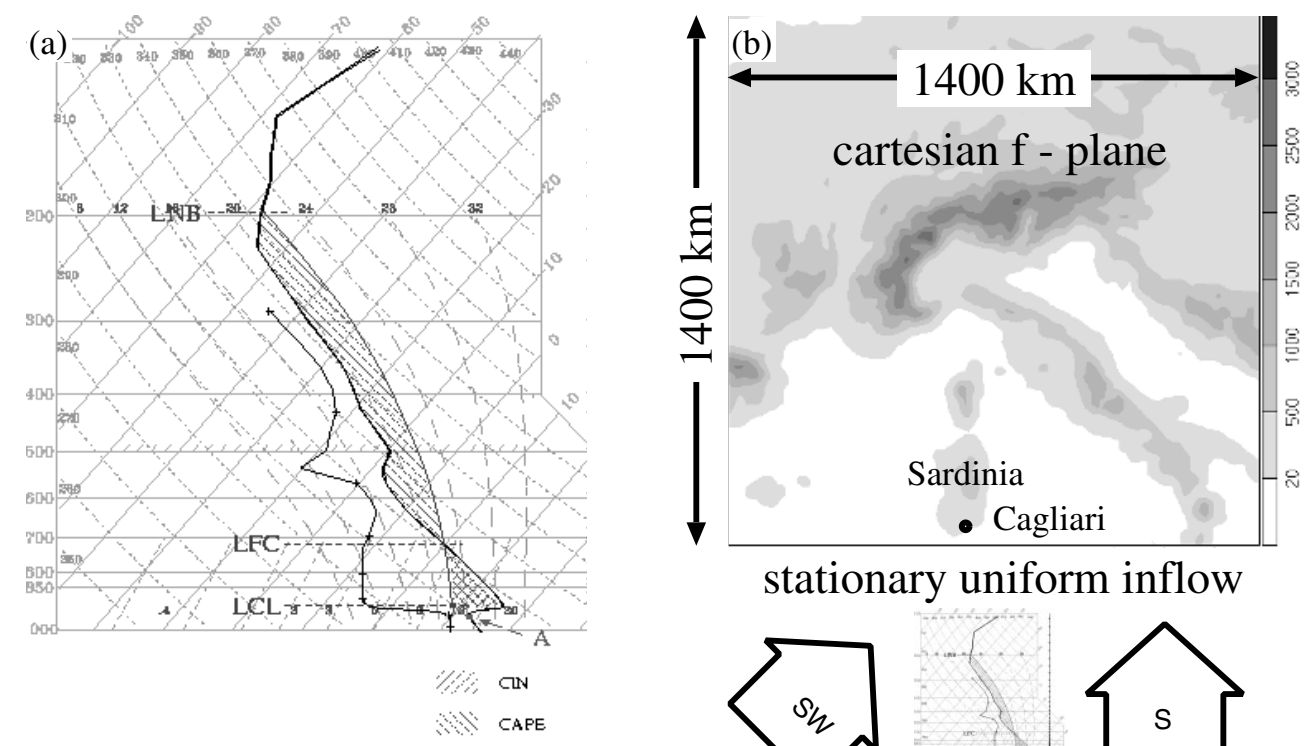

Figure 2. (a) Temperature and dew-point temperature profiles in a $\log P /$ skew- $T$ diagram for the sounding (SYNOP network) launched from Cagliari (the southern tip of Sardinia) 2246 UTC 19 September 1999. (b) Model set-up for the numerical simulations with topography (grey scale, m). Identical topographic contours are used throughout the paper.

the pressure gradient, Coriolis force and planetary boundary layer (PBL) mechanical mixing effects.

For the thermodynamic fields the vertical structure is prescribed in terms of the temperature and humidity (Fig. 2(a)). This structure replicates a sounding launched from Cagliari during MAP IOP2B (Asencio et al. 2003), and comprises a moistureladen (water-vapour content of $15 \mathrm{~g} \mathrm{~kg}^{-1}$ ) conditionally unstable (convective available potential energy $\approx 2000 \mathrm{~J} \mathrm{~kg}^{-1}$ ) maritime boundary layer below $950 \mathrm{hPa}$, which is strongly inhibited (convective inhibition $\approx 200 \mathrm{~J} \mathrm{~kg}^{-1}$ ) by a capping deep stable layer (up to $550 \mathrm{hPa}$ ) of warm and dry air (mean static stability $N \approx 0.0075 \mathrm{~s}^{-1}$, the calculation being based on the dry potential temperature). This vertical structure (sic 'loaded gun') is typical of pre-frontal air masses over the Mediterranean during southAlpine rainstorms (see discussion in Gheusi and Stein (2003)). In addition to its climatological representativity, its structure (a neutral moisture-laden boundary layer capped by a quasi-uniformly stable dry layer) remains simple enough for a rational consideration of flow regimes.

The flow and precipitation regimes in two MAP cases resulting from either conditionally unstable (IOP2B) or moist stable (IOP8) upstream conditions are discussed in Medina and Houze (2003) and Rotunno and Ferretti (2003). Their main conclusions converge with those inferred in the present study although using wind and not stability as the case-dependent parameter.

\section{(b) Numerical model}

Simulations are undertaken with a version of the limited-area mesoscale Europa Modell (EM) of the German (DWD) and Swiss (Meteoswiss) weather services (for full model details see Majewski (1991) and DWD (1995)). The EM is a hydrostatic model 
based on the primitive equations in terrain-following pressure-based hybrid coordinates (Simmons and Burridge 1981). In the present study a research version with $f$-plane cartesian geometry is used. The $f$-plane has a $(1400 \mathrm{~km})^{2}$ horizontal extension and is centred on $\left(45^{\circ} \mathrm{N}, 10^{\circ} \mathrm{E}\right)$ - hence $f \approx 10^{-4} \mathrm{~s}^{-1}$. This domain covers the Alps and surrounding mountain chains (Fig. 2(b)). A single non-nested model is used with a horizontal resolution of $11 \mathrm{~km}$ (corresponding to $0.1^{\circ}$ at the earth's surface) and 37 terrain-following $(\sigma)$ levels with a maximum resolution of $10 \mathrm{hPa}$ near the ground. Representations of the modelled fields will often be shown in this paper at the first model level. This approximately corresponds to $50 \mathrm{~m}$ above the ground level and will be referred to as ' $50 \mathrm{~m}$ AGL'. The lateral boundary treatment uses the standard relaxation scheme (Davies 1976).

For the present study only a few of the model's parametrization schemes are activated. The surface temperature and moisture flux are set to zero to ensure that the thermodynamical properties of the incident flow are solely controlled by the inflow sounding, and the radiative fluxes are also suppressed in the bulk formulation.

In contrast, the subgrid surface drag plays a significant part in the aerodynamics of the low layers so that the terrain roughness and a formulation of the surface layer are considered in the model. The roughness length ranges from $1 \mathrm{~cm}$ for flat land areas up to $80 \mathrm{~cm}$ for high mountainous regions. Over the sea the roughness length implicitly depends on the near-surface wind through the Charnock formula. In the bulk model, the vertical turbulent diffusion of momentum, heat and moisture is ensured through a turbulence scheme with second-order closure of level two in the hierarchy of Mellor and Yamada (1974) (see also Müller 1982).

A Kessler-type formulation is used for the micro-physics of model-resolved clouds and the Tiedtke (1989) mass-flux scheme for the subgrid convective clouds. For deep convection, the latter parametrization sets the updraught moisture flux at the cloud base proportional to the convergence of moisture integrated from the ground up to the condensation level. The performance of parametrized vs. explicitly resolved convection was assessed in Gheusi and Stein (2003) for a very similar physical setting. Although they found significant differences in the precipitation patterns connected to the Apennines, parametrized convection captured the main precipitation features over the Alpine slopes-including at the meso- $\beta$-scale.

Simulations are undertaken for periods of at least $24 \mathrm{~h}$ with $20 \mathrm{~m} \mathrm{~s}^{-1}$ LS flows and $48 \mathrm{~h}$ with $10 \mathrm{~m} \mathrm{~s}^{-1}$ to allow the flow to attain a steady, or quasi-steady, state*

\section{(c) Comments}

The present numerical configuration is comparatively simple and the resolution is not very high. However, it has been successfully tested against:

(i) A similar EM simulation but with twice as fine a resolution $(5.5 \mathrm{~km})$ for a key case (see section 5). Both low-level flow and precipitation distribution show excellent quantitative agreement at low- and high-resolution (Fig. 3).

(ii) A much more refined numerical configuration with the research system MesoNH, that includes non-hydrostatic dynamics, more sophisticated parametrization schemes and two nested models with the innermost at the comparable resolution of $10 \mathrm{~km}$ (the configuration depicted in Gheusi and Stein (2003) but without the highestresolution model). The flows and precipitation distributions over the Alps from EM and

\footnotetext{
* The times given here are sufficient for flows upstream and over the Alps to attain steady-state. Significantly longer periods would be required if considering the Alpine wake regime.
} 


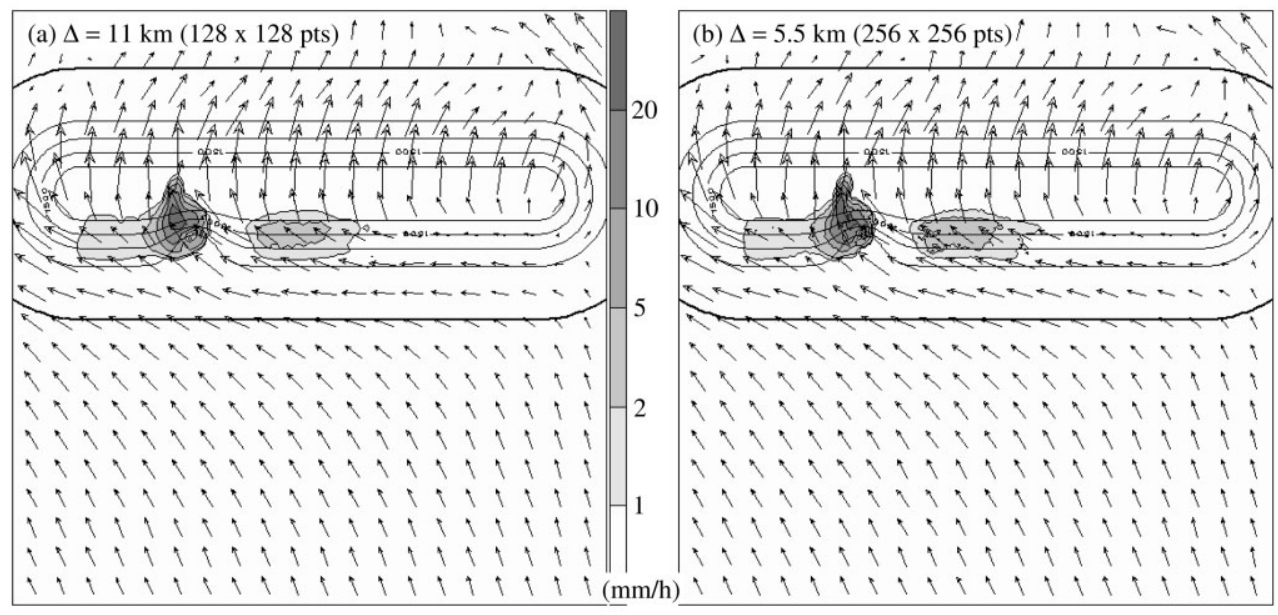

Figure 3. Sensitivity test against model resolution for a southerly $10 \mathrm{~m} \mathrm{~s}^{-1}$ large-scale flow past an idealized barrier including a meso- $\beta$-scale indentation on its upstream side. Stationary hourly precipitation (grey scale, $\mathrm{mm} \mathrm{h}^{-1}$ ) and wind $50 \mathrm{~m}$ AGL (vectors every $55 \mathrm{~km}$ ): (a) low-resolution simulation and (b) high-resolution simulation.

MesoNH are in excellent qualitative and quantitative agreement (the MesoNH simulations can be found in Gheusi (2001), chapter 5).

Note that the LS flow is assumed here to be barotropic and hence the vertical shear (both strength and direction) is attributable purely to mechanical mixing in the PBL. A more realistic incident flow would progressively strengthen and veer eastwards with height in the free atmosphere. However, the thermal-wind balance would imply a horizontal gradient of potential temperature that is not compatible with our assumption of uniform conditions far upstream from the Alps. Anyway, we do not expect that vertical wind shear in the free atmosphere could notably affect the precipitation location and intensity in our simulations, since it is mostly sensitive (through the column convection scheme) to the low-level moisture-laden flow.

Thus the present EM configuration suffices for our goals, including the study of flow dynamics and precipitation over meso- $\beta$-scale topographic features, and its low computational cost permits a wide exploration of flow regimes and a range of sensitivity experiments.

\section{COMPLEX TOPOGRAPHY: LOW-LEVEL FLOW REGIMES}

A sequence of numerical experiments are undertaken with a range of LS-flow strength $\left(5,10,20\right.$ and $\left.30 \mathrm{~m} \mathrm{~s}^{-1}\right)$, and direction (south, south-south-west and southwest), which encompasses the realistic conditions of severe precipitation over the south side of the Alps. Table 1 catalogues the corresponding values of the inverse Froude number $F^{-1}$ and Rossby number $R$ based merely upon the value of the LS flow. Note, however, that the standard criteria for inviscid and adiabatic flow over or around topography (Pierrehumbert and Wyman 1985; Schär and Davies 1987; Davies and Horn 1988) do not apply in the present setting. In particular, the presence of an Ekman-like boundary layer will decrease the strength and change the direction of the incident flow in the lower levels with concomitant, and opposing, changes in $F^{-1}$ and $R$. Likewise, an 
TABLE 1. INVERSE Froude AND ROSSBY NUMBERS CORRESPONDING TO THE LARGE-SCALE FLOW $U_{0}\left(\mathrm{~m} \mathrm{~s}^{-1}\right)$ CONSIDERED IN THE PAPER

\begin{tabular}{lllll}
\hline & 5 & 10 & 20 & 30 \\
\hline$F^{-1}=N H / U_{0}$ & 3.6 & 1.8 & 0.9 & 0.6 \\
$R=U_{0} / f L$ & 0.45 & 0.91 & 1.8 & 2.7 \\
\hline
\end{tabular}

$N=0.75 \times 10^{-2} \mathrm{~s}^{-1}$ is the mean static stability of the deep dry layer in the inflow sounding (Fig. 2(a)); $f=$ $10^{-4} \mathrm{~s}^{-1}$ is the Coriolis parameter; $H=2500 \mathrm{~m}$ and $L=110 \mathrm{~km}$ are the characteristic height and half-width of the Alps, respectively.

alignment of the flow away from normal incidence equates to a less 'effective' incident velocity. Again, release of convective instability would serve to reduce the effective value of $F^{-1}$.

This section overviews the low-level flow regimes that prevail upstream from the Alps for the previously stipulated range of LS-flow conditions.

The streamlines are based on the quasi-stationary horizontal wind field immediately above the surface $(50 \mathrm{~m})$. This near-surface streamline pattern is selected since it provides a quasi-Lagrangian representation of the flow*. Generally the flow features found near the ground and depicted in the text are valid up to about $850 \mathrm{hPa}$ (see, for example, Fig. 8). Above this level the flow tends to progressively align along the LSflow direction and become more uniform in strength. An extensive set of plots of the presented simulations (and also other ones not shown herein) can be found on-line $\dagger$.

\section{(a) Southerly LS flows}

Southerly flows are often considered as a paradigm for rainstorms on the Alpine south side (Buzzi et al. 1998; Buzzi and Foschini 2000; Doswell et al. 1998; SS00; RF01). A variation of the LS-flow velocity from 5 up to $30 \mathrm{~m} \mathrm{~s}^{-1}$ (Figs. 4(a)-(d)) shows a clear change of flow regime from around to over the Alps.

Note that, with surface friction (Figs. 4(a)-(e)), the near-surface flow upstream over the sea has an easterly component due to the leftwards rotation in the Ekman layer. The easterly component decays rapidly with height (down to $10 \%$ of the southerly component within the first kilometre) but nevertheless this directional change is important for the moisture transport towards the Alps since it affects the moisture-laden layer. The eastwards rotation of the near-surface flow is further accentuated by a (more or less pronounced according to the case) deviation along the Apennines and the Dinaric Alps ridges.

A flow-around regime prevails for the $5 \mathrm{~m} \mathrm{~s}^{-1}$ case (Fig. 4(a)). The low-level air at the upstream foot of any relief is strongly deviated leftwards, and guided and accelerated along the mountains (reverse flow is even visible over the Piedmont area). The low-level flow over the Po valley is easterly and merely originates from the Adriatic Sea. The air is directed along the Dinaric Alps then the Alps and appears to be uninfluenced by the two main sub-Alpine indentations of the LM and Friuli areas.

The $10 \mathrm{~m} \mathrm{~s}^{-1}$ case (Fig. 4(b)) still has the main characteristics of the flow-around regime. The jet formed along the Dinaric Alps follows the terrain contours of the Friuli

\footnotetext{
* Streamlines based on the horizontal wind at higher levels do not take the vertical component of the wind into account and so are more difficult to interpret.

$\dagger$ http://www.iac.ethz.ch/ gheusi/EMexperiments/index.html
} 

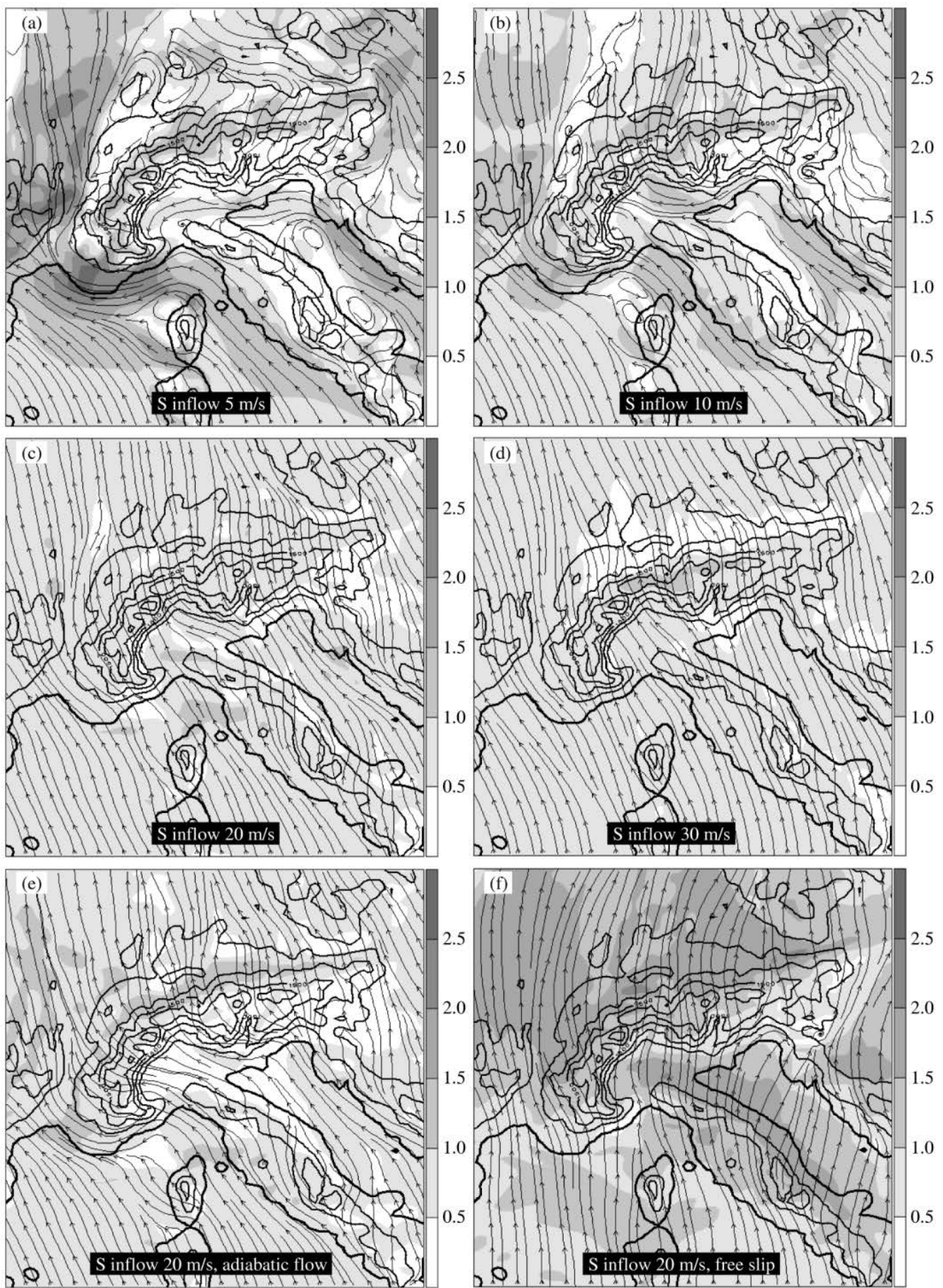

Figure 4. Depiction of the low-level flow regimes for different southerly large-scale (LS) flows or different flow physics. Shown are the $50 \mathrm{~m}$ AGL stationary streamlines and wind velocity normalized with the LS-flow velocity (grey scale). 
concavity and the central Alps. There is a marked barrier-wind jet over the central Po valley that impinges upon the Monte Rosa massif or enters the LM area. In contrast with the $5 \mathrm{~m} \mathrm{~s}^{-1}$ case, however, the flow appears to locally surmount the Alps at the Gotthard Pass.

For the $20 \mathrm{~m} \mathrm{~s}^{-1}$ case (Fig. 4(c)) there is evidence of flow over the Alps but a significant leftwards deviation of the flow still occurs at some places, up to about $850 \mathrm{hPa}$. This regime has to be considered as intermediate between the flow-around and flow-over regimes, classically characterized by dominant horizontal but small vertical motions for the first, and small horizontal but dominant vertical motions for the second. The intermediate flow regime in the $20 \mathrm{~m} \mathrm{~s}^{-1}$ case is hereafter referred to as 'deviatedover'.

Leftwards deviation is especially significant along the central Alps where a barrierwind jet can be identified, which eventually flows into the LM indentation. Unlike the 5 and $10 \mathrm{~m} \mathrm{~s}^{-1}$ cases, the air within the barrier wind does not originate from the Adriatic Sea but crossed over the lower part of the Apennines at the longitude of Venice. A comparable origin has been deduced using backwards trajectories for MAP IOP2b (Asencio et al. 2003). Another notable feature is the channelling of the flow first between Corsica and the Apennines and continuing between the latter and the Maritime Alps. This feature was already noted by Medina and Houze (2003) in the real case of the MAP IOP2b, and is also one of the main findings from the idealized numerical study of Gheusi and Stein (2003). This channelling directs the flow towards the Monte Rosa massif and also causes a local confluence of the air together with the barrier wind just to the east of the massif. Such a convergence of air from the south with the barrier wind can prompt precipitation in this area (RF01).

The $30 \mathrm{~m} \mathrm{~s}^{-1}$ case (Fig. 4(d)) reveals a clear flow-over regime with insignificant horizontal deviation of the streamlines and little variation of the velocity upstream from the Alps. Also evident is a classical acceleration over the crest of the central part of the Alps.

The results of two further sensitivity experiments are presented in Figs. 4(e) and (f) to complement the earlier set of simulations. The first is geared to examining the hypothesis that latent-heat release promotes the flow-over regime. Support for this hypothesis is derived from fully idealized configuration (SSO0) as well as real casestudies (Buzzi et al. 1998; Ferretti et al. 2000). An adiabatic simulation with LS flow at $20 \mathrm{~m} \mathrm{~s}^{-1}$ is shown in Fig. 4(e). It reveals a pattern intermediate between the standard 10 and $20 \mathrm{~m} \mathrm{~s}^{-1}$ cases. As in the $20 \mathrm{~m} \mathrm{~s}^{-1}$ case, the flow is over the Apennines then strongly deviated westwards ahead of the central Alps. In contrast, most of the air from the Thyrrhenian Sea, between Sardinia (Fig. 2(b)) and Italy, flows around the Maritime Alps without penetrating the Po valley. Hence the northern Piedmont and LM areas are exposed merely to a barrier wind without any convergence with air from the south (cf. the standard $10 \mathrm{~m} \mathrm{~s}^{-1}$ case).

The purpose of the second sensitivity experiment is to establish the link with fully idealized studies which adopt a free-slip condition at the lower boundary (e.g. SS00). Figure 4(f) shows the result obtained for $20 \mathrm{~m} \mathrm{~s}^{-1}$ with such a bottom boundary condition. Over and above the suppression of the low-level Ekman rotation, the pattern shows a more pronounced flow-over regime. This is particularly the case over the central Alps. Note that the kinetic energy of the low-level incident flow has been enhanced by the assumption of free-slip at the bottom boundary. This, moreover, permits a marked downslope acceleration on the lee side of the Apennines. Thus the inclusion of surface friction strongly modifies the flow regime for prescribed external values of the main controlling parameters. 

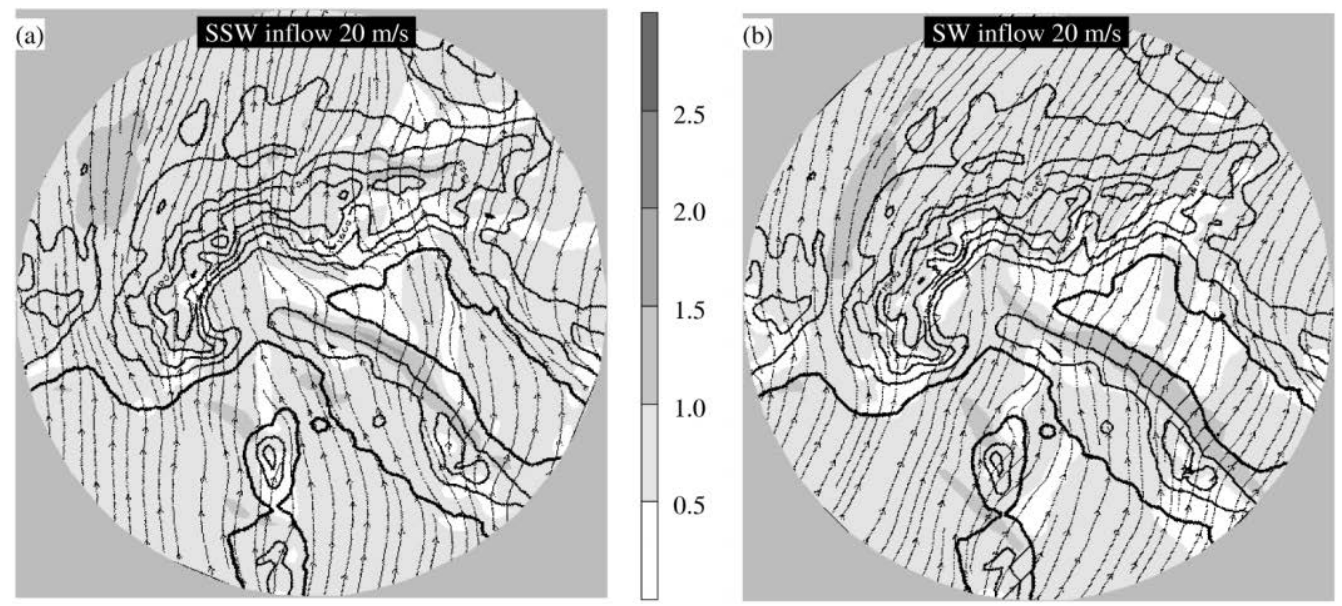

Figure 5. As in Fig. 4 for different large-scale-flow direction with velocity $U_{0}=20 \mathrm{~m} \mathrm{~s}^{-1}$.

\section{(b) South-south-west and south-west LS flows}

Heavy precipitation to the south of the Alps is anticipated for large-scale flows in the entire sector south-west-south. Indeed there were examples of 'south-westerly rainstorms' during the MAP field phase (e.g. IOP5, see Bougeault et al. 2001). Moreover, south-westerly large-scale flows are more frequent than southerly flows since in the former the pressure trough does not require such a deep meridional elongation. It is thus pertinent to explore the influence of the LS-flow direction in the south-west-south sector.

Simulations with south-south-west and south-west $20 \mathrm{~m} \mathrm{~s}^{-1}$ LS flows are shown in Fig. 5. The low-level flow over land in the south-south-west case (Fig. 5(a)) does not differ much from the corresponding southerly case (Fig. 4(c)). This suggests an orographically controlled regime in the low levels for the south-south-south-west sector. In particular, the two main low-level sources of air into the LM area noted in the southerly case (namely, the channelling of air between the Maritime Alps and the Apennines and the barrier wind) are also present in the south-south-west simulation.

In contrast, the south-west experiment (Fig. 5(b)) displays a flow-over regime over the entire Alpine chain with no significant leftwards deviation. The barrier wind is absent and air is channelled between the Maritime Alps and the Apennines directly towards the LM indentation wherein there is an orographically forced confluence. Note that during MAP IOP5 the LS-flow direction was close to south-west and comparable low-level flow features were observed locally over the LM area with dual-Doppler radar measurements (see Bougeault et al. 2001, Fig. 6(a)).

In the above discussion the focus has been on the low-level flow. This has served on the one hand to build a bridge with previous studies of orographic-flow regimes and on the other to extend these studies to a more refined representation of the complex Alpine topography. Previously noted meso- $\alpha$-scale flow-regime features have been identified, along with smaller meso- $\beta$-scale features that appear to be related to comparable scale topographic features such as southerly facing indentations of the Alpine chain and the presence of mountains upstream from the Alps. The implications in terms of the precipitation distribution over the Alps are investigated in the next section. 


\section{COMPLEX TOPOGRAPHY: MOISTURE TRANSPORT AND PRECIPITATION}

The moisture content of the impinging low-level flow plays a major role in determining the orographic precipitation intensity. Very fine-scale numerical simulations (Gheusi and Stein 2003) indicate a close relation between localized enhancement of the precipitation over the Alpine slopes and an orographically induced low-level jet over the Po valley. The low-level transport of moisture and the associated precipitation distribution are now examined for the range of flow regimes studied in the previous section.

To quantify the transport of water vapour we define the water-vapour flux density (hereafter more simply referred to as the moisture flux) as $\mathbf{j}=\rho q_{\mathbf{v}} \mathbf{v}$, where $\rho$ is the density of the air, $q_{\mathrm{v}}$ the specific content in water vapour and $\mathbf{v}$ the wind vector.

In the next two subsections the influence upon the moisture transport and precipitation distribution is studied against the LS-flow direction and then its strength.

\section{(a) Sensitivity to the LS-flow direction}

The precipitation and moisture transport distributions obtained for the $20 \mathrm{~m} \mathrm{~s}^{-1}$ LS flows with different directions from south-south-west to south (corresponding flows presented in section 3(b)) are plotted in Fig. 6. For these settings the rain intensity peaks in the range $12-26 \mathrm{~mm} \mathrm{~h}^{-1}$. Such peak values were also found in both observations or simulations of relatively comparable real events-the 1994 Piedmont flood (RF01); MAP IOP2b (Rotunno and Ferretti 2003; Asencio et al. 2003) —during phases of intense and quasi-stationary rainfall lasting several hours.

The overall precipitation distribution does not differ much between the cases and it is particularly noteworthy that the 'wet spots' are approximately located at the same regions as in the observed climatology (Fig. 1(a)). This weak sensitivity to the LS-flow direction and the qualitative agreement with the climatology* suggest that:

(i) The idealized LS flow for the simulations captures the basic ingredients of typical autumnal Alpine rainstorms;

(ii) the climatological wet spots are attributable primarily to an aerodynamic control of the moisture-laden flow by the orography.

These inferences are supported by the results of SSO0 who showed that a similarly prescribed LS flow and an idealized arc-shaped topography produced a wet spot within the arc. However, the use here of a more realistic representation of the topography enables the model to replicate in finer detail the observed distribution of the climatological wet spots, and this lends further support to the second point (orographic control).

In contrast, more complex flow features have often been invoked as key elements of Alpine south-side rainstorms - uplift associated with a front or upper-level jet (Massacand et al. 1998); presence of a low-level jet (SS00); zonal gradient in the humidity field (RF01). These ingredients can undoubtedly favour or influence convective development over the Alps but the present result suggests that their role might not dominate.

Further inspection of Fig. 6 reveals a close resemblance of the south-south-west and south cases on the scale of a few tens of kilometres. In contrast, the south-southwest simulation does not produce significant precipitation over the slopes of Piedmont.

\footnotetext{
* A quantitative comparison with climatological rain rates is not meaningful since heavy-precipitation events, albeit relatively frequent in the LM area, are not a day-to-day occurrence. The climatological monthly averaged rain rates for October (see at MAP Data Center) are hence much less than those given by the simulations which capture only extreme precipitation events. Nevertheless, the qualitative agreement of the simulations with the rainrate climatology remains valid since the latter shows the wet spots at the same regions as the heavy-rain frequency climatology.
} 

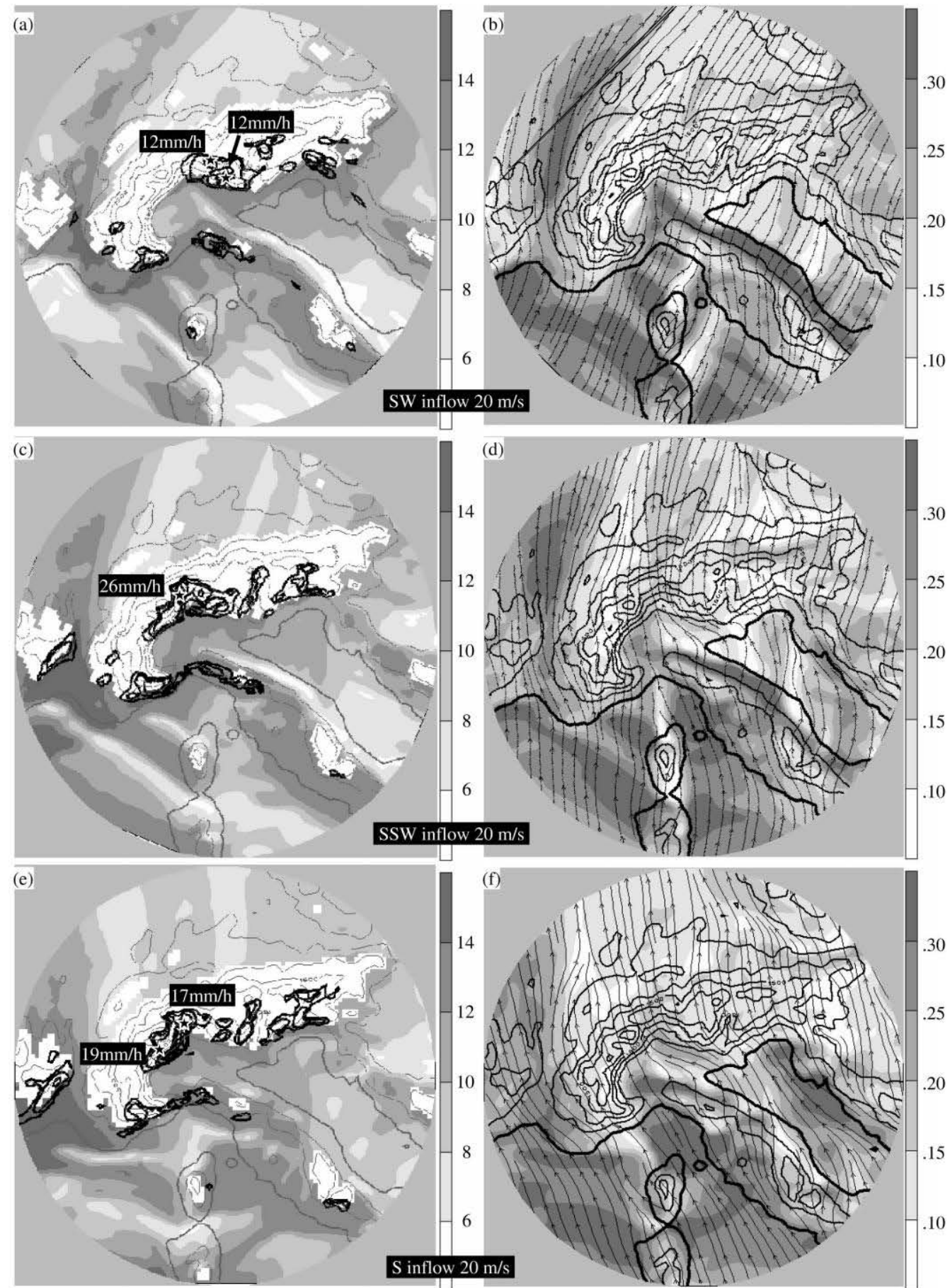

Figure 6. Experiments with $20 \mathrm{~m} \mathrm{~s}^{-1}$ large-scale flows. Left column: water-vapour content at $900 \mathrm{hPa}$ (shading, $\mathrm{g} \mathrm{kg}^{-1}$ ) and hourly precipitation (contours: $2,5,10$ and $20 \mathrm{~mm} \mathrm{~h}^{-1}$ ). Stars mark precipitation peak values. Right column: moisture flux (grey scale, $\mathrm{kg} \mathrm{m}^{2} \mathrm{~s}^{-1}$ ) and stationary streamlines $50 \mathrm{~m}$ AGL. 
Examination of the low-level water-vapour flux (Figs. 6(b), (d) and (f)) shows that in the south-south-west and south cases the transport of moisture up to the Piedmont slopes is mainly associated with the low-level jet channelled between the Maritime Alps and the Apennines which directly impinges on these slopes. In the south-south-west case the orientation of the upstream flow over the Gulf of Genoa results in a channelling towards the LM area while the Piedmont slopes are located in the 'shadow' of the Maritime Alps.

Despite the presence of moisture-laden air over the plain just south of the LM area with comparable moisture content (12-14 $\mathrm{g} \mathrm{kg}^{-1}$ ) in all three cases (Figs. 6(a), (c) and (e)), the precipitation in the LM area is more intense for the south-south-west and south cases than for the south-west case. In the former two cases the barrier wind conveys moisture from the plain into the LM area (Figs. 6(d) and (f)) and appears to be a major source of humidity for the area. The most favourable configuration is realized for the south-south-west case, where the confluence of the channelled and barrier-wind jets occurs to the north-east of the Monte Rosa (Fig. 6(d)) and produces there the most intense in situ rainfall $\left(26 \mathrm{~mm} \mathrm{~h}^{-1}\right)$.

In agreement with Gheusi and Stein (2003) the simulations indicate that heavyprecipitation cores over the Alpine slopes of north-east Italy are related to low-level moisture-transporting jets over the Po valley. These jets exhibit some sensitivity to the direction of the LS flow, but nevertheless heavy precipitation is experienced in the LM area in each of the three investigated cases. The channelled jet compensates the barrier wind for the south-west case, and hence heavy precipitation over LM appears to be comparatively insensitive to the LS-flow orientation.

\section{(b) Sensitivity to the LS-flow strength (south cases)}

Here we consider the moisture transport and precipitation distribution for the different regimes prevailing for southerly LS flows (Fig. 4).

The $10 \mathrm{~m} \mathrm{~s}^{-1}$ LS flow was found to be associated with a flow-around regime and a barrier wind along the Po valley. The water-vapour content is high $\left(12-14 \mathrm{~g} \mathrm{~kg}^{-1}\right)$ and rather uniformly distributed over the Po valley (Fig. 7(a)). The barrier-wind jet appears to be the main carrier of this moisture towards the Monte Rosa massif and the LM area (Fig. 7(b)). The most intense precipitation $\left(25 \mathrm{~mm} \mathrm{~h}^{-1}\right)$ is located over the slopes to the west of the LM area where the upslope flow is further enhanced by horizontal confluence of the barrier wind with air flowing around the Monte Rosa massif. To the south of LM upstream from the Piemontese Alps, the barrier wind decelerates rapidly and the resulting horizontal convergence of moisture is accompanied by a band of moderate precipitation visible over the plain (Fig. 7(b)).

For the $20 \mathrm{~m} \mathrm{~s}^{-1}$ case, precipitation (see Fig. 7(d)) is again concentrated over the slopes exposed to the moisture-laden (12-14 $\mathrm{g} \mathrm{kg}^{-1}$, Fig. 7(c)) low-level flow. In this case, however, the transport of water-vapour towards the slopes to the south of the Monte Rosa is attributable to the channelled jet (Fig. 7(d)) and results in intense precipitation $\left(19 \mathrm{~mm} \mathrm{~h}^{-1}\right)$. The LM area is still supplied with moisture by the barrier wind (as for the $10 \mathrm{~m} \mathrm{~s}^{-1}$ case) and the precipitation to the west of $\mathrm{LM}\left(17 \mathrm{~mm} \mathrm{~h}^{-1}\right)$ is of comparable intensity.

A more detailed examination of the moisture transport in these cases is provided by the vertical cross-sections presented in Fig. 8. The moisture transport is concentrated in the low levels-approximately below the level of the Alpine crest-where the watervapour content is high. However, below $900 \mathrm{hPa}$ this content does not vary much (between 12 and $14 \mathrm{~g} \mathrm{~kg}^{-1}$ ) horizontally so that the moisture flux below $900 \mathrm{hPa}$ is basically modulated by the wind strength (as confirmed by the close correlation of 

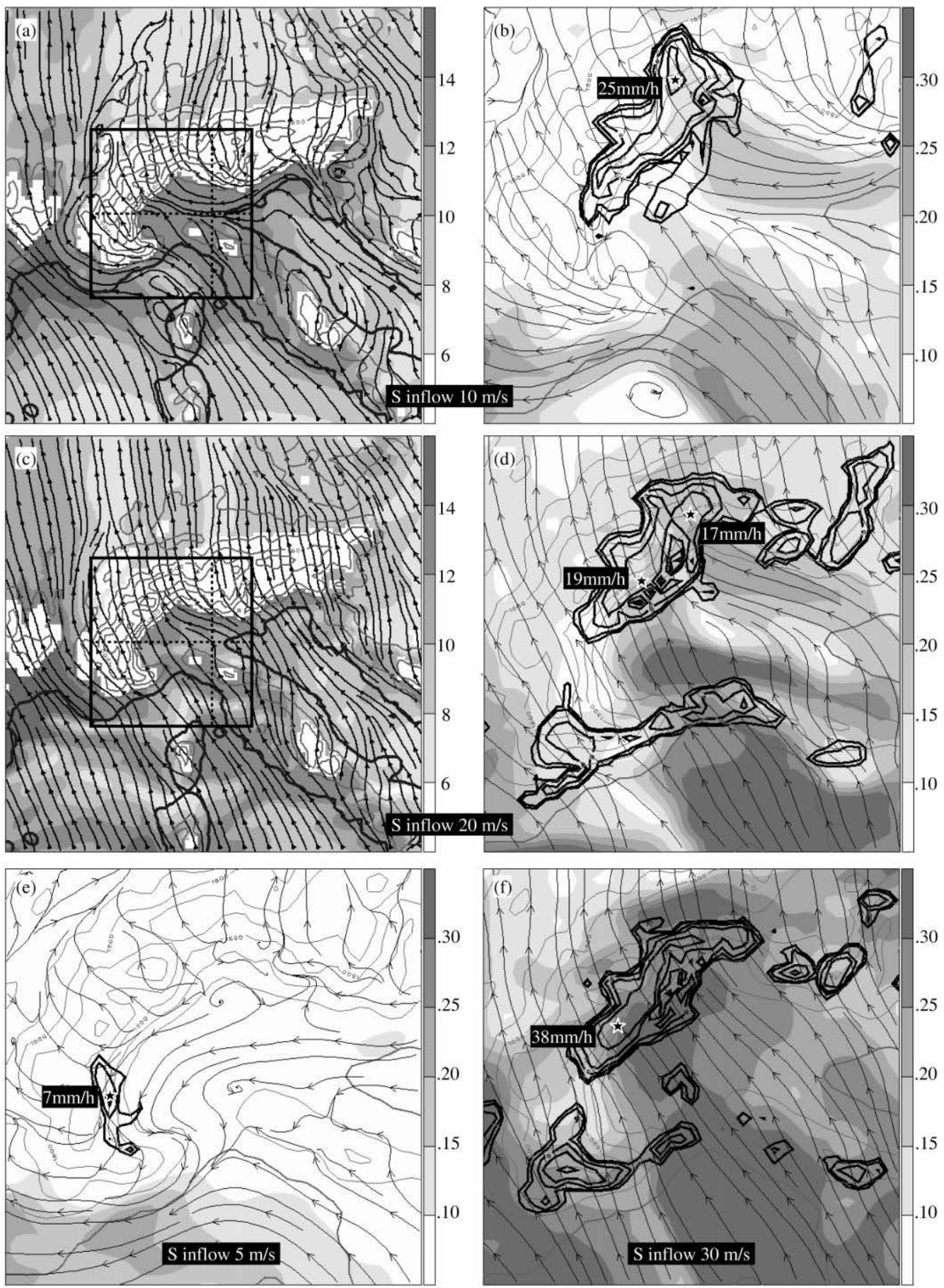

Figure 7. Experiments with southerly large-scale flows. (a) and (c) Water-vapour content at $900 \mathrm{hPa}$ (grey scale, $\mathrm{g} \mathrm{kg}^{-1}$ ) and stationary streamlines $50 \mathrm{~m} \mathrm{AGL}$. (b), (d), (e) and (f) Moisture flux (grey scale, $\mathrm{kg} \mathrm{m}^{-2} \mathrm{~s}^{-1}$ ), hourly precipitation (contours 1, 2, 5, 10 and $20 \mathrm{~mm} \mathrm{~h}^{-1}$ ) and streamlines $50 \mathrm{~m}$ AGL within the subdomain delimited in (a) or (c). Stars mark precipitation peaks. 

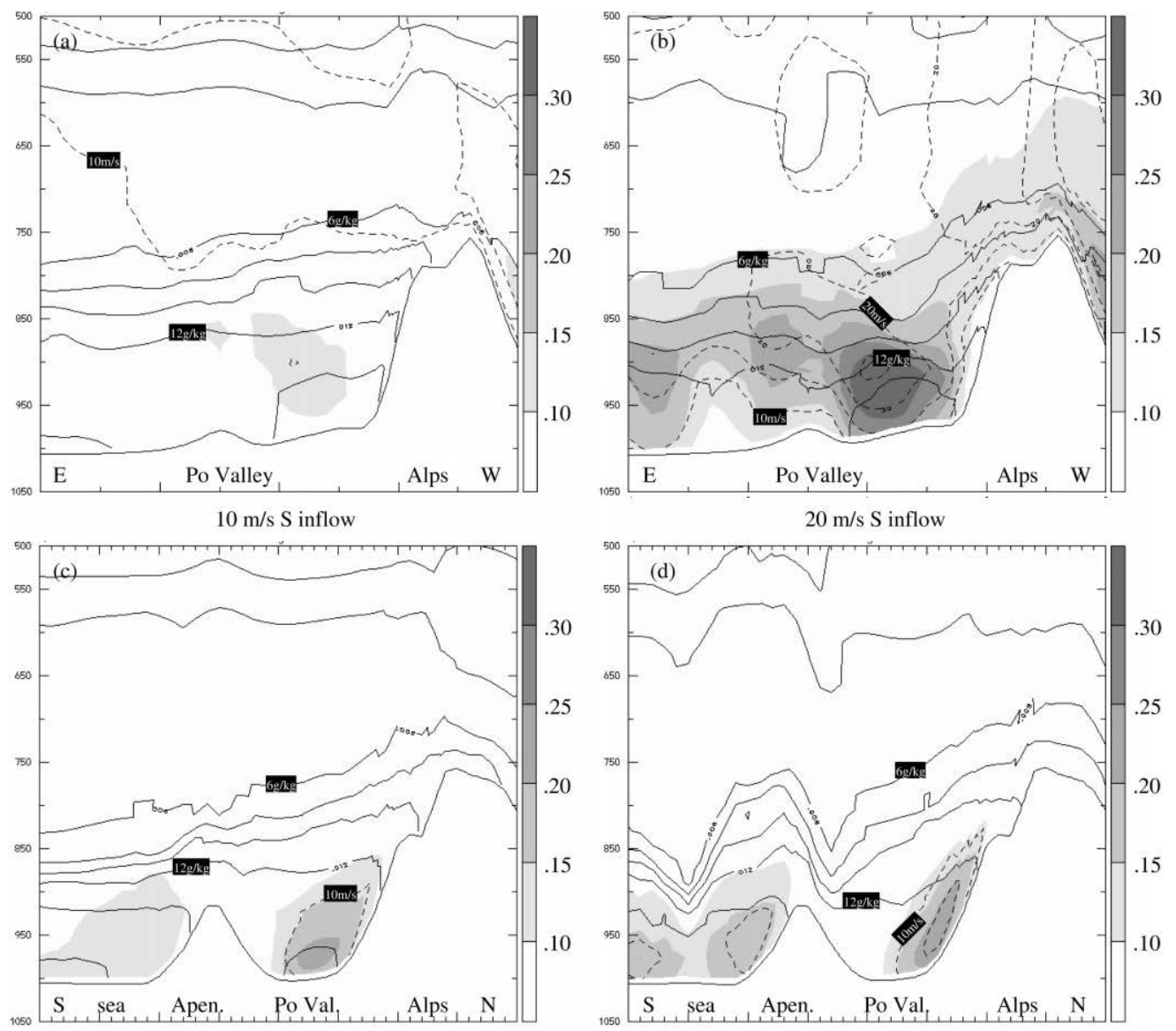

Figure 8. Experiments with southerly large-scale flows: (a) and (c) $10 \mathrm{~m} \mathrm{~s}^{-1}$, (b) and (d) $20 \mathrm{~m} \mathrm{~s}^{-1}$; grey scale denotes moisture flux $\left(\mathrm{kg} \mathrm{m}^{-2} \mathrm{~s}^{-1}\right)$ normal to the plane of the figure; solid contours give specific content in water vapour $\left(q_{v}\right.$, spacing $\left.2 \mathrm{~g} \mathrm{~kg}^{-1}\right)$; dashed contours give wind component normal to the plane of the figure $\left(\geq 10 \mathrm{~m} \mathrm{~s}^{-1}\right.$, spacing $5 \mathrm{~m} \mathrm{~s}^{-1}$ ). (a) and (b) East-west vertical cross-sections along the Po valley indicated in Figs. 7(a) and (c) (positive values for water-vapour flux and wind correspond to a flux out of the figure). (c) and (d) South-north vertical cross-sections across the Po valley indicated in Figs. 7(a) and (c) (positive values for water-vapour flux and wind correspond to a flux into the figure).

the moisture-flux and wind contours). Comparison of the zonal sections confirms the weak moisture transport from the south in the $10 \mathrm{~m} \mathrm{~s}^{-1}$ case (Fig. 8(a)) while the moisture-laden channelled jet is evident in the $20 \mathrm{~m} \mathrm{~s}^{-1}$ case (Fig. 8(b)). In contrast, the meridional cross-sections (Figs. 8(c) and (d)) reveal that the transport of moisture by the barrier wind in the weak LS-flow case $\left(10 \mathrm{~m} \mathrm{~s}^{-1}\right)$ is almost as efficient as for the strong $\left(20 \mathrm{~m} \mathrm{~s}^{-1}\right)$ LS flow, albeit with a notable shift away from the Alpine slopes to a position intermediate between the Alps and Apennines. The difference in the strength of the barrier jet between the two cases is comparatively small. This is consistent with the theoretical deduction (Schär and Davies 1987; Davies and Horn 1988) that for balanced flow 'over' and 'deviated-over' the along-topography flow component is independent of the strength of the incident airstream but merely a function of a Rossby radius of deformation based upon the mountain geometry and LS-flow static stability.

In summary, the precipitation in the LM area is heavy for both the 'around' $\left(10 \mathrm{~m} \mathrm{~s}^{-1}\right)$ and 'deviated-over' $\left(20 \mathrm{~m} \mathrm{~s}^{-1}\right)$ regimes and is attributable to the barrier 
wind that moderates the influence of the LS flow due to its weak dependence upon the latter. In contrast, for the Maritime Alps and the Apennines (cf. Figs. 7(b) and (d)), significant precipitation occurs only for the strongest LS flow.

There is also a more subtle difference in the precipitation distributions in Figs. 7(b) and (d). In the $10 \mathrm{~m} \mathrm{~s}^{-1}$ case a region of moderate precipitation extends well upstream from the Alps over the plain, while in the $20 \mathrm{~m} \mathrm{~s}^{-1}$ case the precipitation is more concentrated in the close vicinity of the slopes. Moreover, in both cases, the barrier wind is the dominating low-level flow feature over the LM area (and hence the main moisture carrier) and precipitation is found preferably over the approximately eastfacing slopes. These two aspects of the simulated distribution also pertain to observed distributions deduced by Houze et al. (2001). Their radar-data-based climatology for two autumnal seasons (including the MAP terrain phase) over the LM area indicated that: (i) the blocking of the low layers induces a region of moderate precipitation largely extending (about one Rossby radius) upstream from the Alps, while in flow-over regimes the precipitation is concentrated (and strongly enhanced) over the windward slopes; (ii) upstream conditions for blocked regimes are well correlated with the easterly orientation of the low-level wind and in turn with precipitation located over the east-facing slopes. The influence of blocked low layer on precipitation (the present $10 \mathrm{~m} \mathrm{~s}^{-1}$ experiment and point (i) of Houze et al. 2001) is spectacularly exemplified in an observation-based case-study by Bousquet and Smull (2003) where blocked low-level cool air blanketing the entire western Po valley rejects any strong convective activity to the Mediterranean while light to moderate stratiform precipitation is observed on the Alps and on the Po valley.

Figures 7(e) and (f) complement the previous considerations for the precipitation distributions in the extreme cases of 5 and $30 \mathrm{~m} \mathrm{~s}^{-1}$, respectively. The great difference in the moisture flux over the Po valley is again almost purely attributable to the variation of the wind strength. In the $5 \mathrm{~m} \mathrm{~s}^{-1}$ case there is some evidence of barrier wind, but the low-layers blocking is sufficient to inhibit upslope lifting and the development of convection. In the flow-over regime $\left(30 \mathrm{~m} \mathrm{~s}^{-1} \mathrm{LS}\right.$ flow) precipitation is produced by direct upslope lifting of the low-level south-easterly flow, resulting in: (i) preferred location of the precipitation being over the south-east exposed slopes; (ii) a good correlation between the precipitation intensity and the steepness of the orography. Note that the precipitation over the slopes of the Piedmont gradually increases with increasing LS-flow velocity from 10 up to $30 \mathrm{~m} \mathrm{~s}^{-1}$ without a noticeable change in the spatial distribution, while the precipitation to the west of the LM area varies less in intensity and is in all cases heavy.

In conclusion, the simulations indicate that heavy precipitation $\left(\gtrsim 15 \mathrm{~mm} \mathrm{~h}^{-1}\right)$ over the LM area is a robust characteristic of the flow for a range of LS-flow strength $\left(\geq 10 \mathrm{~m} \mathrm{~s}^{-1}\right.$ ) and direction (south-west to south). In contrast, the precipitation over many other mountainous areas appears to be more sensitive. This particular result for the LM area suggests that this insensitivity can account for the observed climatological wet spot (Fig. 1(a)).

\section{IDEALIZED TOPOGRAPHIC REPRESENTATIONS}

The results reported in the previous two sections (see also Figs. 4 and 5) were achieved with a comparatively realistic representation of the Alpine topography. They suggest that the enhanced precipitation in the LM region might be linked to both the local relief and the possible presence of a barrier jet incident upon the region from the east. 
Here a further set of experiments is performed with a simpler representation of the terrain in an attempt to isolate the influence of the two aforementioned factors. Our prescribed idealized terrain can be assigned several forms. Its standard form is that of an elongated zonally aligned meso- $\alpha$-scale ridge whose central bi-dimensional part extends over $880 \mathrm{~km}$ and takes the form

$$
h(y)=H \mathrm{e}^{-y^{2} / L^{2}},
$$

where $h$ is height, and with $H=2500 \mathrm{~m}$ prescribing the crest height and $L=110 \mathrm{~km}$ the half-width in the south-north $(y)$ direction. This bi-dimensional form is terminated at its western and eastern tips by an axisymmetric decay with a similar profile.

One variant (see later, section 5(b)(ii)) is to allow the ridge to have an arc shape on its western part. Another variant, adopted in section 5(b), is to refine the topography by introducing a meso- $\beta$-scale southward-facing indentation (cf. the LM area). In this setting the terrain elevation is given by

$$
h(y)\left[1-0.9 \exp \left\{-r^{2} /(L / 2)^{2}\right\}\right],
$$

where $r$ is the horizontal distance from the centre of the indentation which is located a distance $L / 2$ to the south of the ridge crest line.

\section{(a) Flow-regime sensitivity to the LS-flow direction}

In the earlier simulations (sections 3 and 4) the barrier wind (when present) appeared to be the main carrier of moisture to the LM area, and ensured heavy precipitation in that region for a wide range of upstream conditions. Barrier winds have mostly been studied for inviscid flow and elongated ridges and the resulting flow regime depends upon Froude and Rossby numbers based upon the normal flow component (Davies and Horn 1988).

Earlier it was shown that for the LS flow of $20 \mathrm{~m} \mathrm{~s}^{-1}$ the barrier wind was present for both the south and south-south-west settings but not in the south-west case. Thus the orientation of the incident flow relative to the topography constitutes another factor influencing the occurrence of a barrier jet. To examine this aspect we adopt the standard idealized topographic configuration listed above.

Figure 9 shows the near-surface streamlines and the kinetic-energy distribution in orthogonal components for LS flow of $20 \mathrm{~m} \mathrm{~s}^{-1}$ and from the south and south-west. Again the leftwards deviation of the streamlines appears to be much stronger in the south than in the south-west case. The kinetic energy $K$ field in the south case (Fig. 9(a)) shows a clear left-right asymmetry with respect to the barrier, the flow being blocked near the eastern tip of the barrier, whereas the kinetic energy of air parcels does not vary much when flowing over the south side of the central and western part of the barrier. Such an asymmetry is characteristic of the balanced-flow response (see also SS00). In contrast, in the south-west case (Fig. 9(b)), the flow decelerates over the whole span of the barrier on the upstream side.

To distinguish between the flow-over and flow-around tendencies, $K$ is split into cross- and along-barrier kinetic energy $\left(K_{\mathrm{c}}\right.$ and $K_{\mathrm{a}}$, respectively); $K_{\mathrm{c}}$ represents the part of the kinetic energy which is 'effectively' available to overcome the obstacle. The $K_{\mathrm{c}}$ fields for both cases (Figs. 9(c) and (d)) do not differ appreciably, neither far upstream from the barrier nor on the upstream side of the barrier where $K_{\mathrm{c}}$ has decreased by a comparable amount with respect to the value far upstream. However, $K_{\mathrm{c}}$ is converted into different forms of energy in the different cases. In the south case $K_{\mathrm{a}}$ (Fig. 9(e)) increases when the air parcels arrive over the barrier on the upstream side (except over 

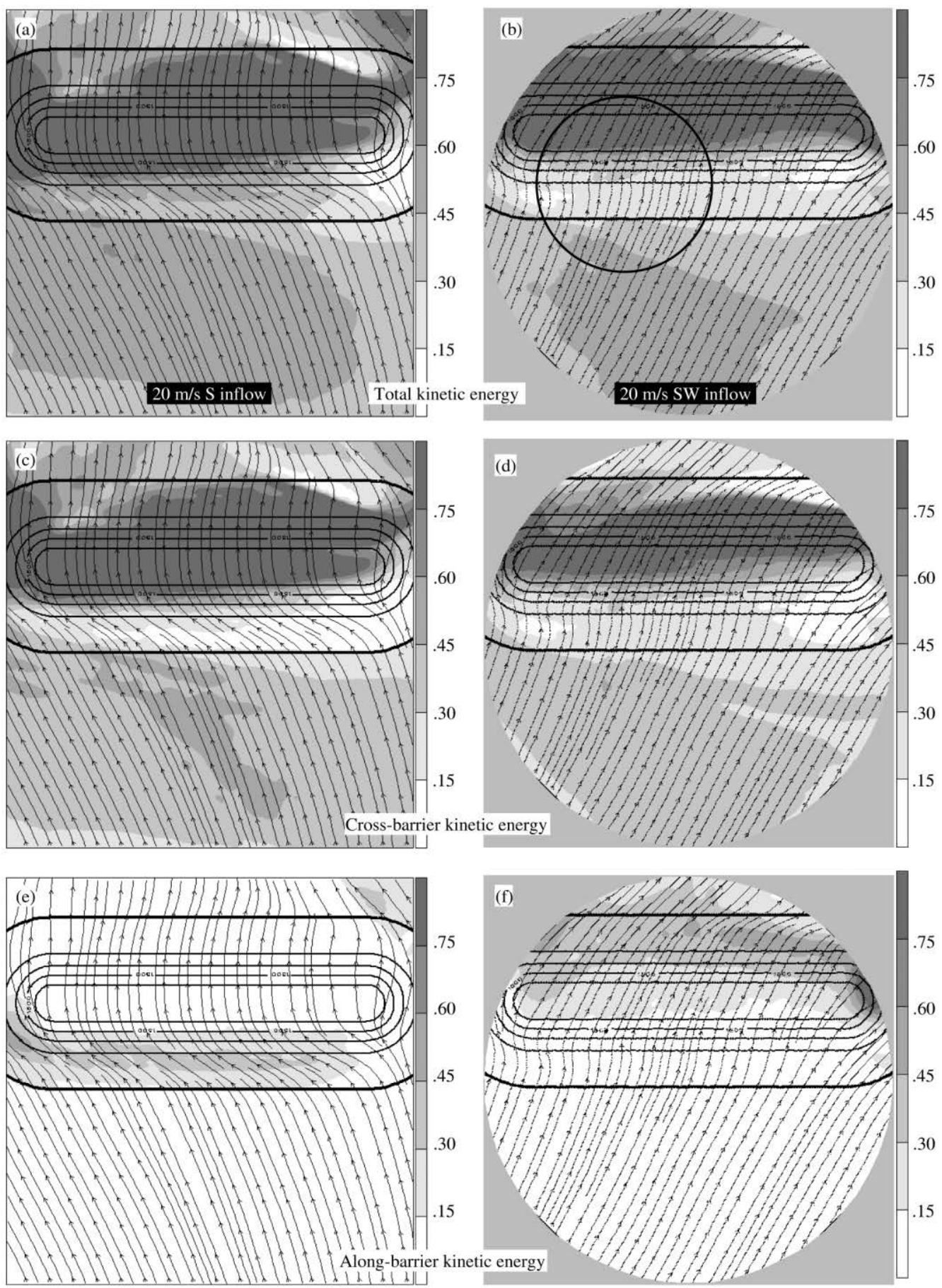

Figure 9. Experiments with $U_{0}=20 \mathrm{~m} \mathrm{~s}^{-1}$ large-scale (LS) flows and on idealized barrier topography: southerly LS flow (left column) and south-west LS flow (right column). Shown are the stationary streamlines $50 \mathrm{~m}$ AGL. Grey scale gives total or partial horizontal kinetic energy normalized with the LS-flow kinetic energy $(1 / 2) U_{0}^{2}=$ $200 \mathrm{~J} \mathrm{~kg}^{-1}$. (a)-(b) Total kinetic energy $K$; (c)-(d) cross-barrier kinetic energy $K_{\mathrm{c}}$; (e)-(f) along-barrier kinetic energy $K_{\mathrm{a}}$. 
the extreme right of the mountain), while the total kinetic energy does not vary much (Fig. 9(a)), consistent with conversion of $K_{\mathrm{c}}$ into $K_{\mathrm{a}}$, i.e. merely horizontal (leftwards) deflection. In the south-west case, both $K_{\mathrm{a}}$ (Fig. 9(f)) and $K_{\mathrm{c}}$ decrease over the upstream slopes and this indicates that kinetic energy is converted into gravitational potential energy to overcome the barrier. A south-west LS flow is not favourable to a flow-around regime since the easterly barrier wind should counter the westerly component of the background flow. Contrariwise, for a southerly LS flow the incident low-level flow has an easterly component. These intuitive arguments point to a need for further study of the dynamics of this sensitivity to the LS-flow direction.

The analogous experiment with south-south-west LS flow (not shown) gives intermediate results between the considered south and south-west cases. The leftward deviation of the streamlines is more significant than in the south-west experiment but it does not result in a well-defined barrier jet. This contrasts with the south-south-west experiment with real topography (Fig. 5(a)). The enhanced flow-around tendency in the latter case is likely to be due to the presence of the Apennines upstream from the Alps: first because the Apennines themselves cause a prior eastwards rotation of the lowlevel flow, which in turn impinges on the central Alps slopes more tangentially; second because the wind is weak over the Po valley just upstream from the Alps, owing to the screening in the lee of the Apennines (visible in Fig. 5(a)).

In effect these experiments with idealized barrier serve to corroborate the findings of section 3, namely a transition from a 'deviated-over' regime in the $20 \mathrm{~m} \mathrm{~s}^{-1}$ south case to a clear 'over' regime when the flow turns to south-west.

\section{(b) Precipitation enhancement by a meso- $\beta$-scale relief indentation}

It was noted earlier that the MAP Science Plan evoked the possible role of subAlpine-scale topographic features in enhancing the precipitation. Here we explore the influence of a meso- $\beta$-scale indentation on the precipitation distribution. Concavities can be found in the Alps at various scales. Previous studies (SSO0, RF01) focused attention on the large-scale concavity associated with the global arc shape of the Alps. Here the focus is on a smaller-scale concavity embedded within the main ridge, e.g. the LM area. The various experiments with real topography showed that, in the vicinity of $\mathrm{LM}$, the moisture is transported at low levels towards the indentation either directly from the south (i.e. normally to the Alpine ridge) or laterally by the barrier wind. Here these configurations will be considered successively.

(i) Flow impinging normally upon an indented ridge. The experiment with southwest $20 \mathrm{~m} \mathrm{~s}^{-1}$ LS flow and real topography studied in section 3 revealed a southerly low-level flow just upstream and over the LM indentation. Likewise, for the idealized barrier-like topography(section 5(a)) the near-surface flow is almost perpendicular to the barrier over the upstream slope in the case of a south-west $20 \mathrm{~m} \mathrm{~s}^{-1}$ LS flow. This simple configuration will be examined first.

The precipitation produced with the south-west $20 \mathrm{~m} \mathrm{~s}^{-1} \mathrm{LS}$ flow and the idealized standard topography is plotted in Fig. 10(a). It can be compared to that produced under identical conditions but with a refined topography including the indentation (Fig. 10(b)). The precipitation is enhanced (more than doubled) within the indentation. This enhancement is well correlated with that of the slope (maximum slope of about $3.5 \%$ in the concavity, whereas it does not exceed $2 \%$ for the simple barrier).

However, the increased slope is in itself not sufficient to explain the enhancement. Figure $10(\mathrm{c})$ presents the result of a sensitivity experiment where the horizontal scale 

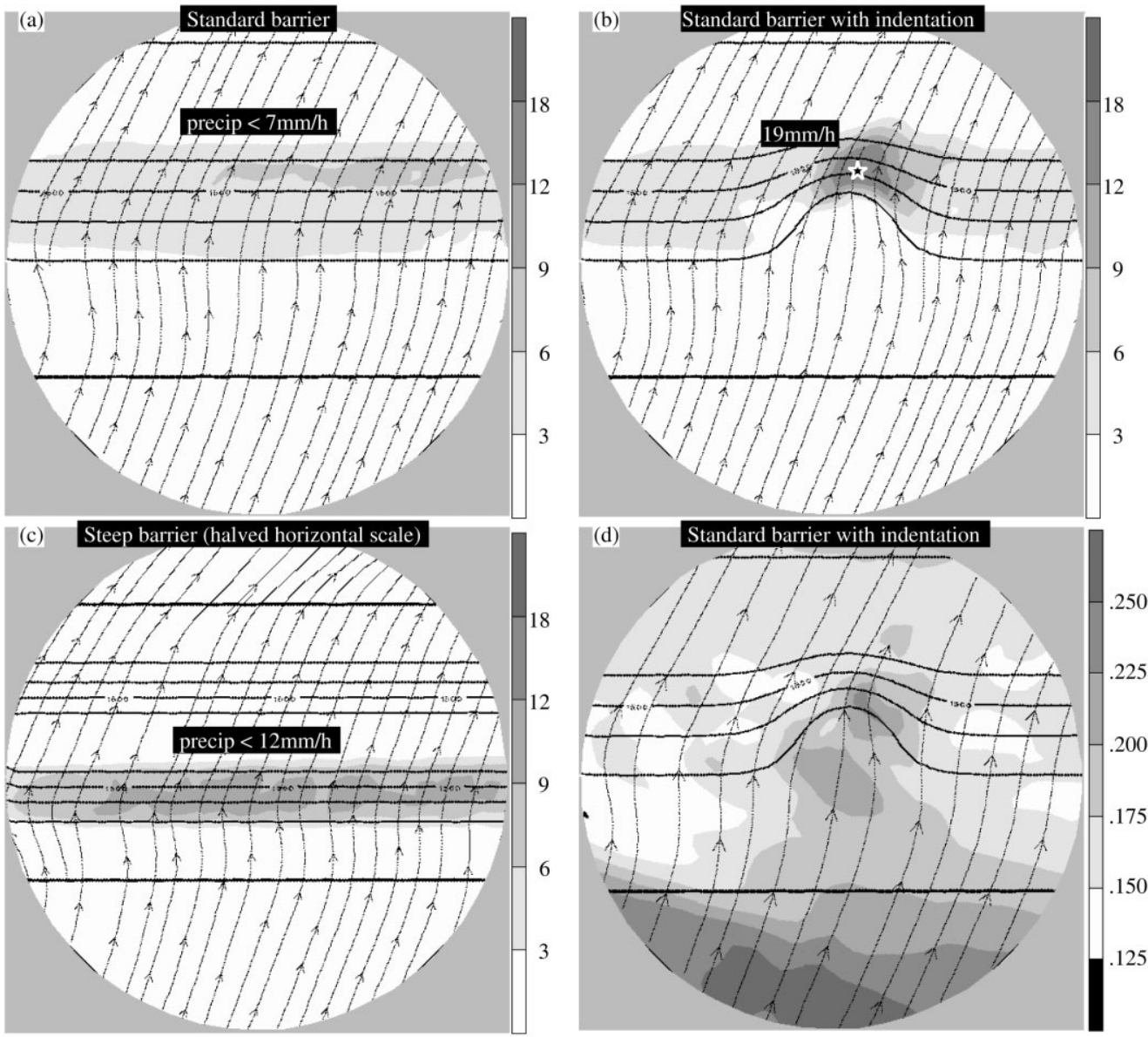

Figure 10. Experiments with south-westerly $20 \mathrm{~m} \mathrm{~s}^{-1}$ large-scale flow and barrier-like obstacles. (a)-(c) Stationary streamlines $50 \mathrm{~m}$ AGL and hourly precipitation (grey scale, mm). (d) Stationary streamlines $50 \mathrm{~m}$ AGL and horizontal moisture flux (grey scale, $\mathrm{kg} \mathrm{m}^{-2} \mathrm{~s}^{-1}$ ). The zoomed domain is indicated with a circle in Fig. 9(b).

$L$ of the standard barrier has been halved so that the maximum slope over the bidimensional part of the steep barrier (4\%) is close to that found in the concavity. The precipitation is more intense than in the case with a standard barrier (Fig. 10(a)), but the enhancement (up to $12 \mathrm{~mm} \mathrm{~h}^{-1}$ ) is less than that within the indentation $\left(19 \mathrm{~mm} \mathrm{~h}^{-1}\right.$, Fig. 10(b)). Another simulation* was performed just like that of Fig. 10(b) (barrier with indentation) but with doubled horizontal length-scales, so that the slope within the indentation (about $1.75 \%$ ) is close to that of the standard barrier (2\%). Again, enhanced precipitation (up to $12 \mathrm{~mm} \mathrm{~h}^{-1}$ ) is found within the indentation compared to $7 \mathrm{~mm} \mathrm{~h}^{-1}$ for the standard barrier (Fig. 10(a)). Furthermore the precipitation is as intense as for the steep (4\%) barrier (Fig. 10(c)). These experiments demonstrate a specific 'indentation effect' at the scale of the LM area that leads to precipitation enhancement.

The near-surface streamlines (Figs. 10(a) or (d)) show that the concavity induces a confluence into it with a local acceleration of the flow and an increased supply in

* Not shown but see http://www.iac.ethz.ch/ gheusi/EMexperiments/index.html 
moisture (Fig. 10(d)). The dynamics of such a flow is likely to be comparable to that of gap flows (but we do not pursue this aspect here).

(ii) Flow along an indented ridge (barrier-wind regime). The southerly $10 \mathrm{~m} \mathrm{~s}^{-1} \mathrm{LS}$ flow for the realistic-topography experiment (sections 3 and 4) leads to a flow-around regime but with heavy precipitation over the LM area associated with moisture supply by the barrier wind. This configuration is idealized here by retaining the southerly $10 \mathrm{~m} \mathrm{~s}^{-1}$ LS flow and replacing the Alps by the standard-barrier topography with or without the LM-like indentation.

The overall low-level flow regime and wind velocity over the standard barrier is shown in Fig. 11(a). Qualitative comparison can be made with the kinetic-energy field in the corresponding $20 \mathrm{~m} \mathrm{~s}^{-1}$ case (Fig. 9(a)). The parcels in the $10 \mathrm{~m} \mathrm{~s}^{-1}$ case-unlike in the latter case where approaching air parcels experienced leftwards deviation but a weak change in velocity-accelerate significantly (up to $1.6 U_{0}$ at $900 \mathrm{hPa}$-not shown) while flowing along the barrier. Thus these experiments with an idealized and isolated barrier again indicate that the barrier wind moderates the changes in the flow far upstream. The westward fluxes of moisture for both cases (not shown) are very similar to each other (both in vertical structure and in intensity) and to those with the real topography (Figs. 8(c) and (d)). Despite the efficient transport of moisture by the barrier wind, little precipitation is produced in the $10 \mathrm{~m} \mathrm{~s}^{-1}$ experiment (less than $3 \mathrm{~mm} \mathrm{~h}^{-1}$, see Fig. 11(a)) since the low-level flow is everywhere quasi-parallel to the slope.

A local modification of the topography so that some slopes are oriented almost perpendicularly to the barrier wind could lead to orographically forced precipitation enhancement, and this is illustrated in Figs. 11(b)-(d) with various topographic shapes.

The meso- $\alpha$-scale arc of the Alpine ridge has been shown to enhance the precipitation within the arc (see SSO0 and to a lesser extent RF01*). The experiment of Fig. 11(b) with an arc-shape obstacle is in the spirit of SS00 (the radius of the crest line in the arc-like part is here of $275 \mathrm{~km}$; the cross-mountain section remains as for the standard barrier) and agrees well with the earlier studies. A local increase in precipitation (up to $8 \mathrm{~mm} \mathrm{~h}^{-1}$ vs. less than $3 \mathrm{~mm} \mathrm{~h}^{-1}$ in Fig. 11(a)) is found within the concavity

The more perpendicular orientation of the slope to the barrier wind might not be the only enhancing factor. The streamlines show some evidence of flow separation near the southern tip of the obstacle, part of the flow being diverted northwards and converging together with the barrier wind at the location of the 'wet spot'. A confluenceinduced wet spot was also among the main conclusions of RF01. They showed that a zonal humidity gradient in the upstream flow, with drier air being present to the east of the Alps, could lead to convergence and enhanced precipitation. This gradient indeed favours a flow around the eastern and central part of the Alps and hence the occurrence of a barrier wind. In the case considered by RF01, the moisture is conveyed from the south since the barrier wind is dry. In contrast, in the present simulation there is no such zonal humidity gradient and the moisture is mainly carried by the barrier wind. This suggests the following generalization of RF01's conclusion: The ingredients for precipitation enhancement in the concavity via convergence relate to (i) occurrence of barrier wind (irrespective of the cause of the flow-around regime along the central

\footnotetext{
* Although this is not among the major results of RF01, their sensitivity experiment recorded in their section 3(c) shows a non-negligible enhancement of the precipitation due to the arc-shape of the Alps.

$\dagger$ South of this wet spot no rainfall is produced although the wind also impinges perpendicularly upon the slope. The easterly wind is there actually much weaker than in the barrier jet farther north (velocity field not shown), and both upslope lifting and moisture transport are insufficient to produce precipitation.
} 

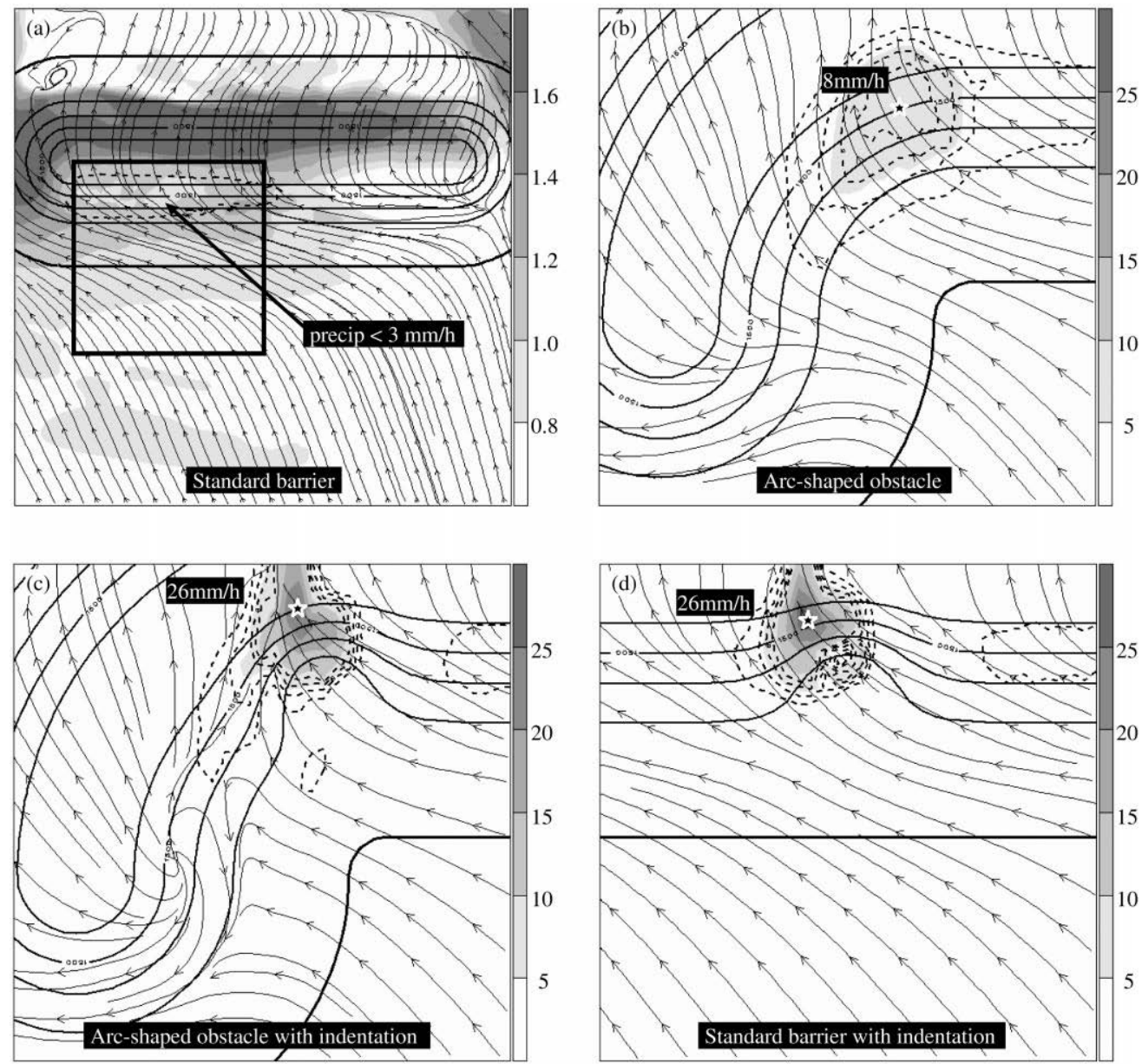

Figure 11. Experiments with southerly $10 \mathrm{~m} \mathrm{~s}^{-1}$ large-scale flow and terrain of various shapes. All panels show the stationary streamlines $50 \mathrm{~m}$ AGL and hourly precipitation (dashed contours, $2 \mathrm{~mm}$ spacing up to $8 \mathrm{~mm}$ ). (a) Grey scale gives wind velocity $50 \mathrm{~m}$ AGL (normalized with large-scale flow velocity $U_{0}=10 \mathrm{~m} \mathrm{~s}^{-1}$ ). The box in (a) locates the zoom domain of (b)-(d). (b)-(d) Grey scale gives hourly precipitation ( $\mathrm{mm}$, with $5 \mathrm{~mm}$ spacing).

Alps-dry dynamics, weak flow velocity, strong stability), and (ii) a moisture supply (irrespective of its origin).

Note that the precipitation in the experiment portrayed in Fig. 11(b) is, however, much less intense than over the LM area in the corresponding experiment with real topography (Fig. 7(b)). Hence meso- $\beta$-scale topographic features might further enhance the precipitation. Figure 11(c) presents a simulation with the arc-shaped obstacle as before but with an added LM-like indentation (as in section 5(b)(i)). The precipitation is markedly more intense and there is excellent agreement (intensity and location of the precipitation distribution) with the real-topography experiment (Fig. 7(b)). Thus the LM-like indentation serves as a major feature for local rain enhancement. This effect is isolated in another experiment (Fig. 11(d)) with the LM-like indentation in the standard barrier (as in section 5(b)(i)). The precipitation resembles that in Fig. 11(c) so closely that the meso- $\alpha$ arc-shape is seen to have a negligible role. In effect, the idealized 

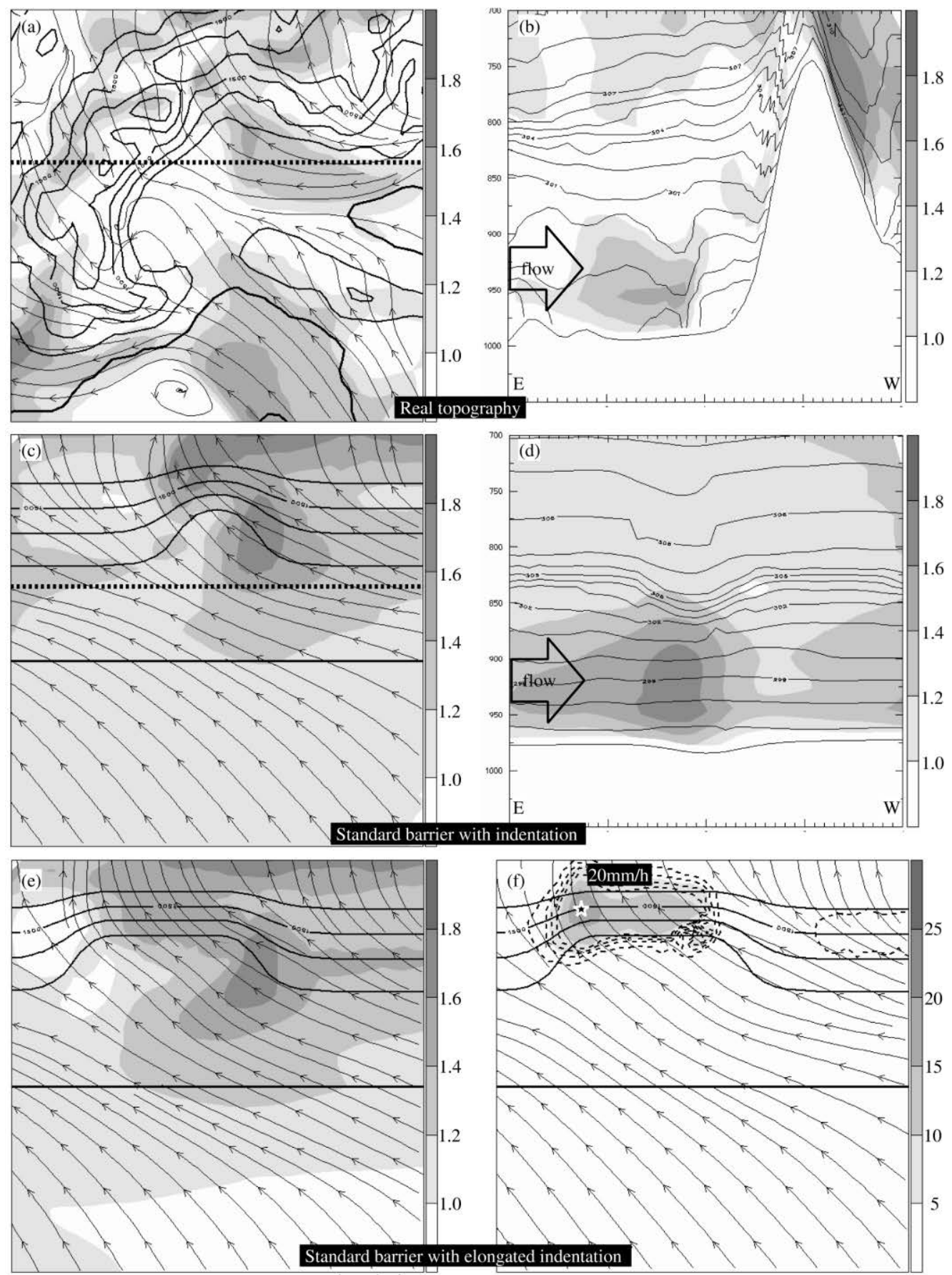

Figure 12. Experiments with southerly $10 \mathrm{~m} \mathrm{~s}^{-1}$ large-scale flow and various topographies. (a), (c), (e) and (f) Stationary streamlines $50 \mathrm{~m}$ AGL. Displayed in (a), (c) and (e) is the wind velocity $50 \mathrm{~m}$ AGL (grey scale, normalized with large-scale flow velocity $U_{0}=10 \mathrm{~m} \mathrm{~s}^{-1}$ ). (b) and (d) East-west vertical cross-sections (indicated with a dashed line in (a) and (c), respectively); wind velocity (grey scale, as in (a), (c) and (e)) and isentropes (1 Kspaced contours). (f) Hourly precipitation (as in Figs. 11(b)-(d)). The thick line in (b), (e) and (f) is the $20 \mathrm{~m}$ terrain contour. 
simulation in Fig. 11(d) appears to capture the main dynamical mechanism that yields the wet spot to the west of LM in the real-topography simulation.

The indentation favours intense precipitation since: (i) the slope at the location of the wet spot is quasi-perpendicular to the moisture-laden wind; (ii) its steepness is greater than in any other settings without indentation. These simple geometric arguments are supplemented by the fact that both horizontal velocity fields in the real-topography (Fig. 12(a)) and barrier + indentation (Fig. 12(c)) experiments show a significant acceleration of the barrier wind just at the entrance of the indentation.

This acceleration is undoubtedly 'indentation induced' since it is absent in the simple-barrier experiment (Fig. 11(a)). Figures 12(b) and (d) show vertical east-west oriented (i.e. approximately along the low-level flow) sections across these acceleration cores. In both cases the acceleration region is associated with downward-sloping isentropes. In the idealized case in particular (Fig. 12(d)), the acceleration is clearly linked to the drop of the thermal inversion layer. Such a flow feature in association with the local topographic configuration can be interpreted in terms of supercritical hydraulic flow in two possible settings: (i) the flow over a meso- $\beta$-scale valley that is characterized by significant acceleration on the downslope; (ii) the flow around a cape where the horizontal diffluence downstream from the cape leads to acceleration in an expansion fan (Burk et al. 1999; see also the appendix). In both cases the acceleration is due to consumption of gravitational potential energy (consistent with downflow sloping isentropes) accompanying the divergent shape of the guiding boundary (downsloping topography in case (i); divergent lateral constraint in case (ii)). Note that these two mechanisms are physically similar and are not mutually exclusive.

In particular, evidence for hydraulic dynamics around a cape is supported by an experiment (Figs. 12(e)-(f)), where the indentation has been elongated to isolate the cape-like topographic feature. The resulting acceleration core around the 'cape' is quite similar to that of Fig. 12(c). The sudden deceleration along an oblique line corresponds to a hydraulic jump (its vertical structure, not shown, is very close to that in Fig. 12(d)). Such jumps along an oblique line with respect to the coast are also among the results of Burk et al. (1999).

Note that the jump is (at least near the slope) associated with weak precipitation (Fig. 12(f)). Jumps are also present in the real-topography (Fig. 12(a)) and barrier + indentation (Fig. 12(c)) experiments with associated moderate precipitation (Figs. 7(b) and 11(d), respectively).

The precipitation distribution in the case with barrier and elongated concavity (Fig. 12(f)) produces, as in the case with standard LM-like indentation (Fig. 11(d)), a precipitation maximum over the slopes to the west of the indentation, i.e. where the topography is both steep and almost normal to the impinging flow. In the case with standard LM-indentation, however, the precipitation was significantly more intense because the suitably oriented slope was located just downstream from the 'cape'induced jet. This favourable configuration is also sustained with the real topography (Fig. 7(b)). Thus the topography in the LM area has the appropriate scale and shape to allow that type of dynamical mechanism, leading to localized but severe precipitation enhancement.

\section{CONCLUSION}

A two-staged systematic model-based exploration of rain-producing flow regimes south of the Alps has been conducted. 
First, for a complex and realistic representation of the Alpine topography the model was forced at its lateral boundaries with a simplified uniform and stationary large-scale flow of prescribed geostrophic velocity and direction. The explored LS-flow parameter space extends, respectively, from 5 to $30 \mathrm{~m} \mathrm{~s}^{-1}$ and from south-west to south (i.e. flows with dominant southerly component) and covers most of the meteorological conditions known to lead to south-Alpine rainstorms. The study focused on the aerodynamic factors influencing orographic precipitation enhancement associated with various flow regimes.

Considering the flow at the scale of the whole Alpine ridge (meso- $\alpha$ scale), the regimes range continuously from the classical directly 'over' to 'around' regimes. Intermediate regimes (here termed 'deviated-over') exhibit the standard east-west asymmetry of balanced flows with blocking and deviation along the eastern extent of the barrier but flow over the western part. Two complementary results emerged from this set of simulations:

(i) The influence of the boundary-layer mixing is considerable since: (i) a reduced velocity in the low levels shifts the regime towards flow-around in comparison with similar configuration with free-slip; (ii) the Ekman rotation modifies the flow direction of the whole moisture-laden layer (rotation with respect to the LS flow is as strong as $30^{\circ}$ or more near the ground).

(ii) The nature of the flow regime depends on the direction of the LS flow. Flow-over is favoured in the case of a south-west large-scale geostrophic flow since the leftwards deviation (due to both Ekman rotation and upstream orographic influence) orientates the incident flow perpendicular to the barrier. In contrast, for a southerly LS flow the streamlines tend to align along the barrier and this configuration is more favourable to a flow-around regime and the occurrence of barrier wind. For example, with a $20 \mathrm{~m} \mathrm{~s}^{-1}$ LS flow (which is quite typical for south-Alpine rainstorms), a 'deviated-over' regime is obtained for the south and south-south-west LS flows while the regime is fully 'over' in the south-west case.

In relation to the precipitation distribution, a qualitative agreement is found in the location of the 'wet spots' between the 'representative' simulations $\left(20 \mathrm{~m} \mathrm{~s}^{-1} \mathrm{LS}\right.$ flow) and the climatology of heavy precipitation. This suggests that the wet spots result primarily from an orographic aerodynamic control of the low-level moisture-laden flow.

In a second stage, attention is focused on the enhancement of the precipitation over the Lago Maggiore (LM) area. It is shown that this occurs for a wide region of the explored LS-flow parameter space. This can account for the extremely high climatological frequency of heavy precipitation events observed over the LM area.

The systematic rain enhancement in the vicinity of LM is linked to mechanisms isolated using complementary simulations undertaken with suitably idealized topography. These mechanisms can be classified into two scale ranges: (i) at the meso- $\alpha$ scale (geostrophic or weakly ageostrophic flows at the scale of the Alpine chain); (ii) at the sub-Alpine scale where aerodynamical effects due to meso- $\beta$-scale topographic features-in particular the LM indentation-dominate. The key aspects of the associated dynamics can be summarized as follows:

\section{(i) Meso- $\alpha$ scale.}

(a) In the flow-over regime, the precipitation is mainly driven by direct orographic uplift and located over the steepest slopes facing counter to the local low-level wind.

(b) In intermediate regime ('deviated-over'), the flow passes over the Apennines before being significantly deviated by the central Alps to form a barrier-wind jet. The latter contributes mainly to moisture transport towards the LM area. Another possible 
moisture supply is due to the channelling of marine air between the Apennines and the Maritime Alps. These mountains induce a low-level jet over the western Po valley directed as is the low-level flow over the Gulf of Genoa. It thus impinges upon the Alps at various locations, for instance the Piemontese Alps for a southerly LS flow, or the LM area for a south-west LS flow, and causes there intense precipitation.

(c) In the flow-around regime, the barrier wind is the sole carrier of moisture towards the LM area, but its intensity varies weakly with the strength of the LS flow. Thus the precipitation in the LM area is heavy even with a moderate $\left(\approx 10 \mathrm{~m} \mathrm{~s}^{-1}\right)$ upstream flow.

(ii) Local aerodynamic regimes near Lago Maggiore (meso- $\beta$ scale). Previous studies (e.g. SS00 and to a lesser extent RF01) suggested the overall meso- $\alpha$-scale arched shape of the Alps favours low-level convergence within the concavity and thereby promotes in situ precipitation. Herein it is suggested that a smaller meso- $\beta$-scale orographic indentation, such as the LM area, can lead locally to an enhancement of the precipitation with a much greater efficiency, due to the following two disparate dynamical processes:

(a) In the case of a southerly low-level flow just upstream and over the LM indentation, the precipitation enhancement is not only due to uplift on the steeper slopes, but there is also an 'indentation effect' due to (i) acceleration of the flow entering the concavity (cf. gap flows) and (ii) forced horizontal convergence.

(b) In the cases where a barrier wind is present, the flow may have some similarity with a coastal supercritical hydraulic flow around a cape (Burk et al. 1999). As long as the barrier wind is flowing along the Alps, it remains constrained in a narrow jet over the upstream side. When entering the LM concavity this lateral constraint is relaxed and the local diffluence of the flow makes it accelerate. This in turn strengthens the upslope wind and the precipitation on the west side of the concavity.

Finally, the present set of simulations are in harmony with the observation-based climatological study by Houze et al. (2001). In particular they show that a flow-around regime in the Po valley: (i) leads to precipitation in the LM area that occurs preferentially on the eastward-facing slopes (i.e. those perpendicular to the barrier wind), and (ii) allows weak or moderate precipitation to occur a few tens of kilometres upstream from the Alps over the plain, owing to low-level blocking.

Clearly many aspects on Alpine humid-flow regimes remain to be more fully investigated in order to establish a rigorous regime diagram. The present study provides an introduction to, and a glimpse of, the subtle range of effects that will be an integral aspect of such a diagram.

\section{ACKNOWLEDGEMENTS}

We are grateful to Daniel Lüthi (ETH Zürich) for his support and advice concerning the numerical model, and to Joël Stein (Météo-France) for supervising the preliminary work for this study.

\section{APPENDIX}

\section{Shallow-water flow in a channel with varying width}

Let us consider a stationary inviscid shallow-water flow guided in a channel of varying width $l$ in the along-channel direction $x$. The channel width $l(x)$ is assumed to vary 
so slowly that vertical and cross-channel velocity components remain everywhere negligible with respect to the along-channel component $u$. Assumption of one-dimensionality is further made for $u=u(x)$.

The governing equations are thus the momentum equation along $x$,

$$
u \frac{\partial u}{\partial x}=-g \frac{\partial \eta}{\partial x},
$$

where $\eta(x)$ is the local depth of the water layer, $g$ is the acceleration due to gravity, and the continuity equation is

$$
\frac{\partial}{\partial x}(\ln u)=0 .
$$

(This equation system is inspired by, for example, Baines (1995, chapter 2).)

Eliminating $\partial u / \partial x$ between Eqs. (A.1) and (A.2) yields

$$
\left(1-\frac{u^{2}}{g \eta}\right) \frac{\partial \eta}{\partial x}=\frac{u^{2}}{g l} \frac{\partial l}{\partial x}
$$

The supercritical-flow condition is $u^{2} / g \eta>1$. In this case a widening of the channel $(\partial l / \partial x>0)$ implies a drop of the free surface $(\partial \eta / \partial x<0)$ and (according to Eq. (A.1)) an acceleration of the flow.

A more refined formulation and theory are proposed by Drobinski et al. (2001).

Asencio, N., Stein, J., Chong, M. and Gheusi, F.

Baines, P. G.

1995

Bougeault, P., Binder, P., Buzzi, A., 2001 Dirks, R., Houze, R.,

Kuettner, J., Smith, R. B.,

Steinacker, R. and Volkert, H.

Bousquet, O. and Smull, B. F.

Burk, S. D., Haack, T. and

Samelson, R. M.

Buzzi, A. and Foschini, L.

Buzzi, A., Tartaglione, N. and Malguzzi, P.

Davies, H. C.

Davies, H. C. and Horn, J.

Doswell, C. A., Ramis, C., Romero, R. and Alonso, S.

Drobinski, P., Dusek, J. and

DWD Flamant, C.

Ferretti, R., Low-Nam, S. and Rotunno, R.

2003

1999

1976

1988

1998

2001

1995

\section{REFERENCES}

Analysis and simulation of local and regional conditions for the rainfall over Lago Maggiore Target Area during MAP IOP 2b. Q. J. R. Meteorol. Soc., 129, 565-586

Topographic effects in stratified flows. Cambridge University Press

The MAP Special Observing Period. Bull. Am. Meteorol. Soc., 82, 433-462

2003 Observations and impacts of upstream blockings during a widespread orographic precipitation event. Q. J. R. Meteorol. Soc., 129, 391-409

Mesoscale simulation of supercritical, subcritical and transcritical flow along coastal topography. J. Atmos. Sci., 56, 2780-2795

2000 Mesoscale meteorological features associated with heavy precipitation in the southern Alpine region. Meteorol. Atmos. Phys., $\mathbf{7 2}, 131-146$

1998 Numerical simulations of the 1994 Piedmont flood: Role of orography and moist processes. Mon. Weather Rev., 126, 23692383

A lateral boundary formulation for multi-level prediction models. Q. J. R. Meteorol. Soc., 102, 405-418

Semi-geostrophic flow of a stratified atmosphere over elongated isentropic valleys and ridges. Tellus, 40A, 61-79

A dignostic study of three heavy precipitation episodes in the western Mediterranean region. Weather and Forecasting, 13, $102-124$

Diagnostics of hydraulic jump and gap flow in stratified flows over topography. Boundary-Layer Meteorol., 98, 475-495

Dokumentation des EM/DM-Systems. Deustcher Wetterdienst (available from Deutscher Wetterdienst, Zentralamt, D63004 Offenbach am Main, Germany)

Numerical simulations of the Piedmont flood of 4-6 November 1994. Tellus, 52A, 162-180 
Frei, C. and Schär, C.

Gheusi, F.

Gheusi, F. and Stein, J.

Houze Jr, R. A., James, C. N. and Medina, $\mathrm{S}$.

Majewski, D.

Marwitz, J. D.

Massacand, A. C., Wernli, H. and Davies, H. C.

Medina, S. and Houze, R. A.

Mellor, G. L. and Yamada, T.

Müller, E.

Pierrehumbert, R. T. and Wyman, B.

Rotunno, R. and Ferretti, R.

Schär, C. and Davies, H. C.

Schneidereit, M. and Schär, C.

Simmons, A. J. and Burridge, D. M. 1981

Tiedtke, $\mathrm{M}$.
1998 A precipitation climatology of the Alps from high-resolution raingauge observations. Int. J. Climatol., 18, 873-900

2001 'Analyses eulériennes et lagrangiennes des systèmes convectifs quasi-stationnaires sur les Alpes'. PhD thesis, Université Toulouse III (available from the author in electronic version)

2003 Small-scale rainfall mechanisms for an idealized convective southerly flow over the Alps. Q. J. R. Meteorol. Soc., 129, 1819-1840

2001 Radar observations of precipitation and airflow on the Mediterranean side of the Alps: Autumn 1998 and 1999. Q. J. R. Meteorol. Soc., 127, 2537-2558

1991 'The Europa-Modell of the Deutscher Wetterdienst'. Pp. 147-191 in Proceedings of ECMWF seminar on numerical methods in atmospheric models, Vol. 2, 9-13 September 1991. ECMWF, Reading, UK

1987 Deep orographic storm over the Sierra Nevada. Part I: Thermodynamic and kinematic structure. J. Atmos. Sci., 44, 159-173

1998 Heavy precipitation on the Alpine south-side: An upper-level precursor. Geophys. Res. Lett., 25, 1435-1438

2003 Air motions and precipitation growth in Alpine storms. Q. J. R. Meteorol. Soc., 129, 345-371

1974 A hierarchy of turbulent closure models for planetary boundary layer. J. Atmos. Sci., 31, 1791-1806

1982 'Turbulent flux parametrization in a regional-scale model'. Pp. 193-220 in Proceedings of workshop on planetary boundary layer parametrization, November 1981. ECMWF, Reading, UK

1985 Upstream effects of mesoscale mountains. J. Atmos. Sci., 42, 9771003

2001 Mechanisms of intense Alpine rainfall. J. Atmos. Sci., 58, 17321749

2003 Orographic effects on rainfall in MAP cases IOP 2b and IOP 8. Q. J. R. Meteorol. Soc., 129, 373-390

1987 Quasi-geostrophic stratified flow over finite amplitude topography. Dyn. Atmos. Oceans, 11, 287-306

2000 Idealised numerical experiment of Alpine flow regimes and southside precipitation events. Meteorol. Atmos. Phys., 72(2-4), 233-250

An energy and angular momentum conserving vertical finite difference scheme and hybrid vertical coordinates. Mon. Weather Rev., 109, 758-766

A comprehensive mass flux scheme for cumulus parametrization in large-scale models. Mon. Weather Rev., 117, 1779-1800 